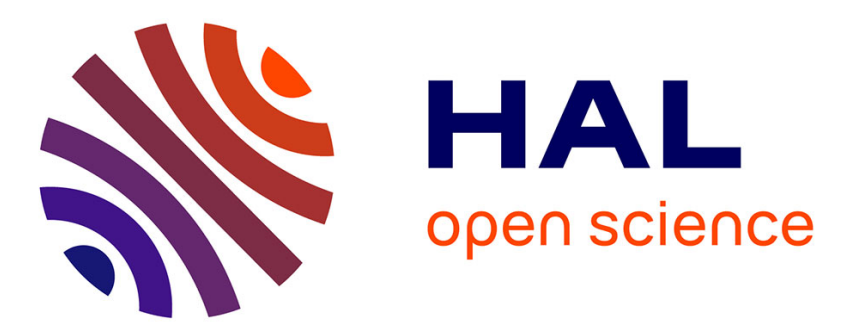

\title{
Anomalous Diffraction Approximation for light scattering cross section: case of ordered clusters of non-absorbent spheres
}

\author{
Sandra Jacquier, Frédéric Gruy
}

\section{- To cite this version:}

Sandra Jacquier, Frédéric Gruy. Anomalous Diffraction Approximation for light scattering cross section: case of ordered clusters of non-absorbent spheres. Journal of Quantitative Spectroscopy and Radiative Transfer, 2008, 109 (5), pp.789 à 810. 10.1016/j.jqsrt.2007.09.003 . emse-03434309

HAL Id: emse-03434309

https://hal-emse.ccsd.cnrs.fr/emse-03434309

Submitted on 18 Nov 2021

HAL is a multi-disciplinary open access archive for the deposit and dissemination of scientific research documents, whether they are published or not. The documents may come from teaching and research institutions in France or abroad, or from public or private research centers.
L'archive ouverte pluridisciplinaire HAL, est destinée au dépôt et à la diffusion de documents scientifiques de niveau recherche, publiés ou non, émanant des établissements d'enseignement et de recherche français ou étrangers, des laboratoires publics ou privés. 


\title{
Anomalous Diffraction Approximation for light scattering cross section: case of ordered clusters of non-absorbent spheres
}

\author{
Sandra Jacquier and Frédéric Gruy * \\ École Nationale Supérieure des Mines de Saint-Étienne Centre SPIN, Département GENERIC, 158 Cours \\ Fauriel 42023 St. Étienne
}

\begin{abstract}
Anomalous Diffraction (AD) method has proved to be an adequate approximation of the exact method (GMM code computed by $\mathrm{Xu}$ ) to obtain the scattering cross section for aggregate whose the primary particle size parameter is upper than 2 . Indeed, the error of this approximated method is less than approximately $10 \%$ when the primary particles are in $\mathrm{SiO}_{2}$.

However this method is strongly related to the aggregate morphology since it includes in its formulation the concept of chord length. We initially studied the chord distribution for various aggregates, and then we reformulated the anomalous diffraction method, to approximate the scattering cross section, now completely analytically. This new expression is entitled ADr with the $r$ for rapid because this one is at least a hundred times faster than the standard AD method.
\end{abstract}

Keywords: Aggregate, Light Scattering, Anomalous Diffraction, Scattering Cross Section, Chord Length Distribution

\section{Introduction}

Many industrial operations involve solid-liquid suspensions which are agitated resulting in collisions and in the subsequent aggregation of particles. This phenomenon is due to Brownian motion in the case of sub-micronic particles and the velocity field heterogeneity in the case of larger particles. The formed aggregates usually contain few primary particles because large aggregates undergo fragmentation which leads to a size limit for the aggregates. Generally, in these suspensions aggregates are composed of less than one hundred primary particles. Primary particles and aggregates are composed of various materials with high refractive index as titania for instance, intermediate refractive index as alumina or small refractive index as silica. The suspending medium is often water. Some applications need to know the optical properties of aggregates with low refractive index material: silica, ice crystal, gas hydrate crystal, pharmaceuticals in water. The on-line characterization of the suspension is made by spectral turbidimetry [1] which is defined as the total attenuation of a light beam due to scattering and absorption by particles. In order to analyze the turbidity measurements, scattering cross sections of aggregates are needed.

There exist several techniques which can render an exact method as explained by F.M. Kahnert [2] to express these cross sections. We have chosen the GMM (Generalized Multiparticle Mie solution) developed by Y-L. Xu in 1995 [3] and borne out by experimental

*Corresponding author. Tel :+33(0)4 77420057 ; fax :+33(0)4 77499694

E-mail address : fgruy@emse.fr (F. Gruy), jacquier_sj @yahoo.fr 
verification [4]. GMM is an extension of Mie theory for the case of multiple (spherical and/or non-spherical) particles. It is based on the superposition principle derived from the solution of Maxwell's and wave equations, with the standard electromagnetic boundary conditions on a surface separating two media.

Moreover, aggregates in suspension may move and present several random orientations to the light beam. Thus, only averaged scattering cross section is relevant to turbidity analysis. The GMM code is interesting because one can obtain an averaged scattering cross section over all possible orientations [5] (for more information see the references therein).

We consider that an aggregate to be composed of $\mathrm{N}$ identical primary spherical particles. The radius and the dimensionless size parameter of the primary particles are denoted $\mathrm{r}$ and $\mathrm{x}=2 \pi r / \lambda$ respectively ( $\lambda$ is the wavelength of the incident light in the medium). Then, scattering cross sections depend on: the size of the primary particles, morphology of the aggregates, and relative refractive index. The relative refractive index $(\mathrm{m})$ is the ratio between the primary particle refractive index $\left(\mathrm{n}_{\mathrm{p}}\right)$ and refractive index of the medium $\left(\mathrm{n}_{\mathrm{m}}\right)$.

This exact, but complicated, GMM theory cannot be easily used to interpret turbidity spectra on-line, for instance. This is due to the time-consuming calculations needed for large amounts of different aggregates (doublets, triplets...) which can be produced during the aggregation process.

In a previous work [6,7], we compared the exact method to several different approximated methods among which was the Anomalous Diffraction (AD) which gives the aforementioned scattering cross section. We concluded that AD, which takes into account the shape of the aggregate, is a efficent approximation for a aggregate composed of primary particles with large size parameters (larger than 2).

The topic of this paper is to decrease this method's computing time, by reformulating analytically for cluster of spheres.

We will initially summarize earlier work on Anomalous Diffraction applied to the case of a sphere and an aggregate. Then we will evaluate the aggregate chord length distribution which will be then used in the AD formulation. Finally, the performance of this new formulation will be compared with respect to the exact method.

\section{Background on Anomalous Diffraction (AD)}

\subsection{Principles}

Anomalous diffraction approximation [8] provides a method by which the scattering properties of a particle can be rapidly obtained for the large size parameter and small optical contrast. We will sum up as follows:

Large particles usually refract strongly and may also absorb. In this case the reflected and refracted components of the scattered light are dissipated into an angle larger than where diffraction is significant. A negligible amount of the defused light interferes with the diffracted. 
However, for very soft scatters where $m \square 1$, this is not the case. Here, the refracted rays propagate almost without a change of direction and interfere with the diffracted component. This phenomenon is termed anomalous diffraction and evidently occurs when $x \square 1$ and $|m-1| \square 1$ (see the discussion of Videen and Chylek [9] and Liu [10] on this validity ranges).

The second condition implies that the rays are slightly deviated when they cross the interface particle-medium and that the reflexion is negligible with the same interface. The extinction is thus due to:

- absorption of the light passing through the particles

- $\quad$ interferences between the light passing through the particle and that going around.

Anomalous Diffraction approximation was applied to a sphere and an infinitely long circular cylinder [8], a prism column [11], a hexagonal crystal of ice [12], ellipsoids [13], a finite cylinder [14] and various forms ([15], [16]).

In this paper we consider aggregates of spherical primary particles. Thus we will re-examine $\mathrm{AD}$ formulation in the case of a sphere and a cluster of spheres.

\subsection{Sphere}

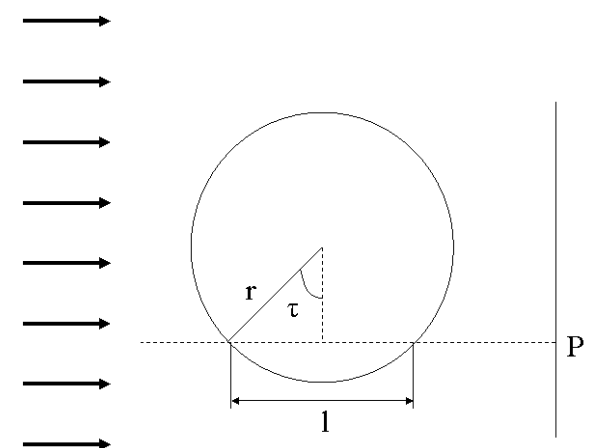

Figure 1: Ray passing through a sphere [8]

On Figure 1 represents the path of a ray (called $l$ ) inside a spherical particle with a radius $r$.

The phase difference between a ray passing through the sphere and a ray passing outside is: $k(m-1) l=k(m-1) 2 r \sin \tau(\mathrm{k}=2 \pi / \lambda$ is the wave vector in the medium)

We lay down $\rho=2 x(m-1)$

The scattering efficiency $Q_{\text {ext }}$ is proportional to the amplitude function $S(0)$ [8]:

$$
Q_{\text {ext }}=\frac{4}{x^{2}} \mathfrak{R} e\{S(0)\} \text { with } S(0)=\frac{k^{2}}{2 \pi} \iint\left(1-e^{-i \rho \sin \tau}\right) d x d y
$$

The integrand represents the contribution of shadow (1) minus that of rays passing through the sphere $\left(e^{-i \rho \sin \tau}\right)$.

If $\mathrm{m}_{\mathrm{r}}$ is real:

$$
Q_{s c a}=Q_{e x t}=2-\frac{4}{\rho} \sin \rho+\frac{4}{\rho^{2}}(1-\cos \rho)
$$

Then

$$
C_{s c a}=Q_{s c a} S_{p}
$$


$S_{p}$ represents the projected area $\left(S_{p}=\pi r^{2}\right.$ for a sphere).

\subsection{Aggregates}

In the case of an aggregate, the step remains the same, namely to determine the chord length $l$. Moreover, we made the remark in [6] that morphology had its importance for the great size parameters of the primary particle. AD approximation makes it possible to consider the aggregate morphology as well:

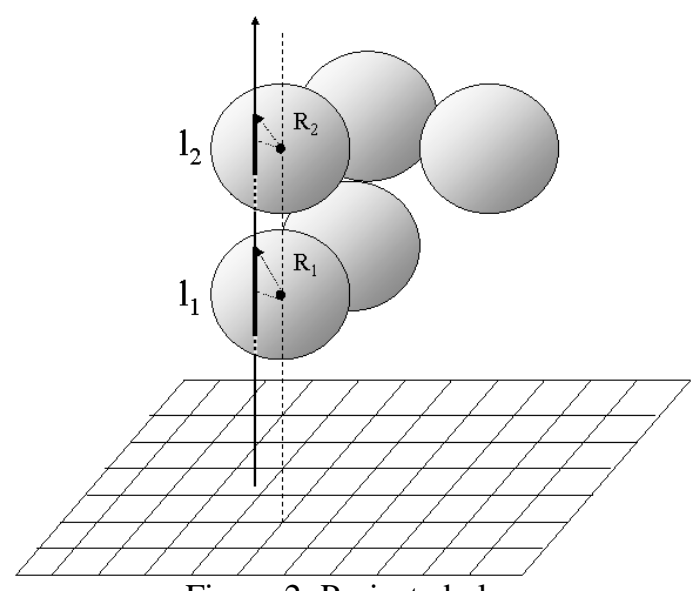

Figure 2: Projected plan

The various possible chords (or intercepts) are evaluated: $l_{1}, l_{2} \ldots$ and are introduced into the equation (4) to obtain the scattering cross section $\mathrm{C}_{\mathrm{N}}$ of the $\mathrm{N}$-aggregate:

$$
C_{N}=2 r^{2} \iint_{[S p]}(1-\cos x l(m-1)) d S_{p}
$$

With $l(x, y)=\sum_{i=1}^{N} l_{i}(x, y)$

Integration is performed over the object projected area $S_{p}$ on a plane perpendicular to propagation direction. $l$ is the computed path of light through the object, which is a function of the projection coordinates $\mathrm{x}$ and $\mathrm{y}$. Lengths $\left(l, l_{\mathrm{i}}\right)$ and area $\left(\mathrm{S}_{\mathrm{p}}\right)$ are made dimensionless by dividing them by the primary particle radius. Note: this kind of calculation was previously carried out for fractal (large) clusters by Khlebtsov [17].

Average $\mathrm{C}_{\mathrm{N}}\left(\left\langle\mathrm{C}_{\mathrm{N}}\right\rangle\right)$ is obtained while rotating the aggregate on itself (or by changing the projection plane) and then by carrying out the average over all the discrete angle values (5).

$$
<C_{N}>=2 r^{2}\left\langle\iint_{[S p]}(1-\cos x l(m-1)) d S_{p}\right\rangle_{\theta}
$$




\subsection{AD and chord length distribution}

Since the evaluation of the chord length is the relevant parameter of the AD method, we reformulated the $\mathrm{AD}$ approximation according to the chord length distribution.

\subsubsection{Formulation}

The chord length distribution notion (CLD) is presented as follows: $D(l) d l$ represents the number fraction of the chord length in the range $[l, l+d l]$. Thus, $D(l)$ obeys the normalization equation:

$$
\int_{0}^{l_{\max }} D(l) d l=1
$$

$l_{\max }$ is the maximum chord length of an aggregate.

The CLD can be used to define the Anomalous Diffraction rapid approximate method: $\mathrm{ADr}$ is known to be faster than standard AD. The chord length distribution $D(l)$, which depends on the morphology of the aggregate, is used to calculate the scattering cross section :

$$
<C_{N}^{r}>=2 r^{2}<S_{p}>\int_{0}^{l_{\max }}(1-\cos x l(m-1)) D(l) d l
$$

$\left.<S_{p}\right\rangle$ is the projected area averaged over all orientations of the aggregates.

\subsection{2. $\quad$ CLD of a single sphere and spheroid}

The chord length distribution $D(l)$ for a sphere is:

$$
D(l)=l / 2
$$

with $l \in[0 ; 2]$ ( the chord length distribution for a sphere is the same no matter what projection angle $\theta$ ).

By applying this chord length distribution in the equation (7), the expression (3) is obtained. We can thus conclude that this new formulation is partially in agreement with the previous.

Moreover the aggregate chord length distribution is not accessible analytically. It was, thus, necessary to check if a calculation algorithm, led to similar results to those obtained analytically for the simple case of a spheroid (Annex A). On Figure 3a (sphere) and Figure 3b (spheroid), the histogram represents the numerical chord length distribution obtained on the whole of $10^{6}$ possible chords, with the analytical chord length distribution represented by a continuous line. These two distributions are in agreement. 


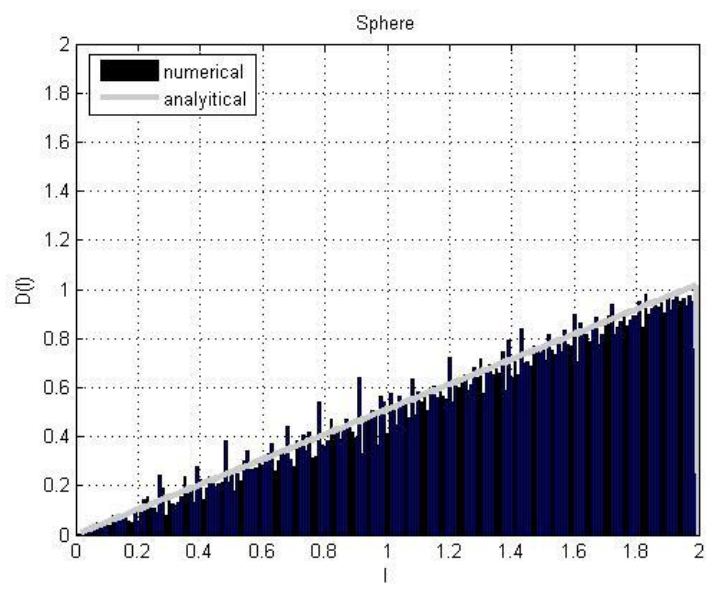

a)

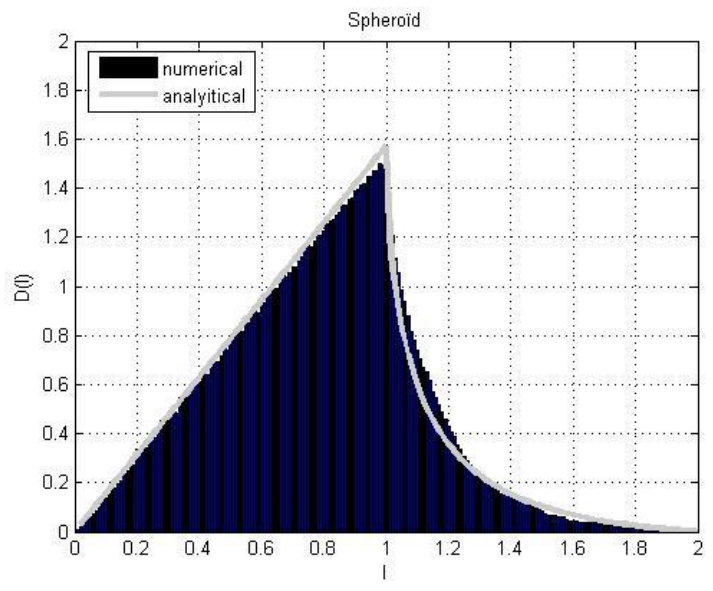

b)

Figure 3: Chord length distribution for a sphere a ) and a prolate spheroid b). The ratio of the major and minor semi-axis is equal to 2 . The dimensionless size $l$, it is the ratio between the chord length and: the particle radius a), the major semi axis length $b$ ).

\subsubsection{Scattering Cross Section of a spheroid}

$\mathrm{Q}$ is define as the ratio of the average of the spheroid scattering cross section and the projected surface of an equivalent volume sphere to the spheroid in question ( $r_{V}$ is the equivalent sphere radius).

$$
Q=\frac{<C>}{\pi r_{v}^{2}}
$$

The AD method uses the equation (5) (dashed grey line in Figure 4), ADr (dashed dark line in Figure 4) uses the equation (7) with $\mathrm{D}(\mathrm{l})$ previously obtained by numerical simulation with the algorithm (Annex B). One can see that $\langle C\rangle=\left\langle C^{r}\right\rangle$ for a spheroid. The corresponding proof is shown in Annex C. These two calculations techniques are checked by the comparison to the analytical average scattering cross section which is available for a spheroid (Annex C) and plotted as a dark line in the Figure 4. 


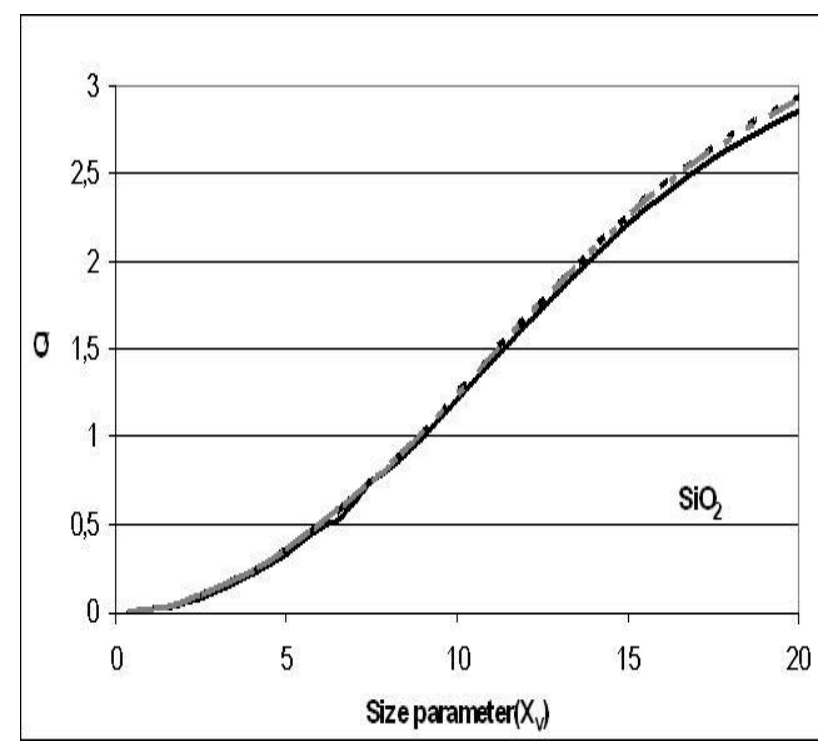

a)

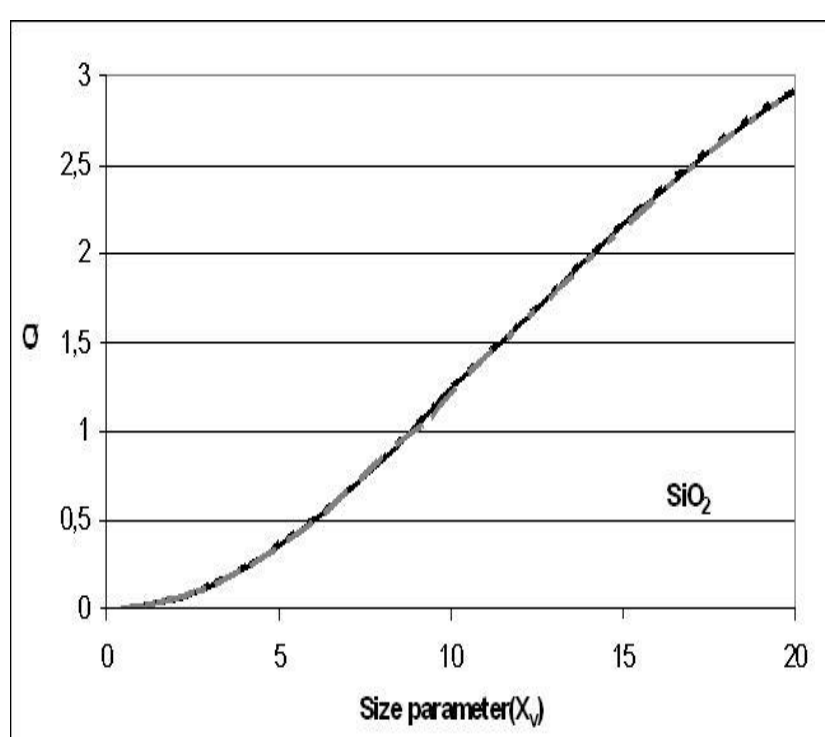

b)

Figure 4: Comparison of $\mathrm{AD}$ and $\mathrm{ADr}$ methods : $\mathrm{Q}$ as a function of the equivalent sphere size parameter $\left(x_{v}=k r_{v}\right)$, for $\mathrm{SiO}_{2}(\mathrm{~m}=1.08)$ and a spheroid: oblate (a) and prolate (b). The ratio of the major and minor semiaxis is equal to 2 and 0.5 respectively.

As illustrated in the figures, whatever the type of spheroid (prolate or oblate), the numerical results are in agreement with the analytical. Therefore, the notion of CLD will be used for describing the object morphology and will be useful as an intermediate function for the calculation of scattering cross sections (7). Thus, CLD will be used in the case of the aggregates.

\section{Aggregate chord length distribution}

In this section, the chord length distributions, previously defined, will be determined for aggregates beginning with a table of the examined morphologies.

\subsection{Aggregate configuration}

The Table 1 presents the aggregate morphology which will be studied. 
Table 1: Aggregate configuration

\begin{tabular}{|c|c|c|c|c|c|c|}
\hline & linear & compact & plan & cubic & spherical & random \\
\hline $\begin{array}{c}4 \\
\text { spheres }\end{array}$ & & & $2 * 2$ & - & - & \\
\hline $\begin{array}{c}8 \\
\text { spheres }\end{array}$ & 8 & & $2 * 4$ & - & - & \\
\hline $\begin{array}{c}16 \\
\text { spheres }\end{array}$ & 16 & & $4 * 4$ & $2 * 2 * 4$ & - & \\
\hline $\begin{array}{c}25 \\
\text { spheres }\end{array}$ & - & - & $5 * 5$ & - & - & - \\
\hline $\begin{array}{c}32 \\
\text { spheres }\end{array}$ & - & & - & - & - & - \\
\hline $\begin{array}{c}33 \\
\text { spheres }\end{array}$ & - & - & - & - & & - \\
\hline $\begin{array}{c}40 \\
\text { spheres }\end{array}$ & 40 & - & - & - & - & \\
\hline $\begin{array}{c}64 \\
\text { spheres }\end{array}$ & 64 & - & $8 * 8$ & $4 * 4 * 4$ & - & - \\
\hline $\begin{array}{c}100 \\
\text { spheres }\end{array}$ & 100 & - & $10 * 10$ & $5 * 5 * 4$ & - & - \\
\hline
\end{tabular}

In this paper, only well ordered aggregates (linear, planar, cube) will be studied. We also present a sphere (rounded cube) consisting of primary spherical particles. The last column contains random aggregates in order to show possible differences from well ordered aggregates. 


\subsection{Exact aggregate chord length distribution}

The figures $(5,6,7)$ represent the chord length distribution of aggregates:

linear and compact configurations (with 2, 4, 8 and 16 primary particles)

Figure 5a through g,

- $\quad$ cubic configuration (with 64 and 100 primary particles) Figure 6 a \& b,

- $\quad$ spherical configuration (with 33 primary particles) Figure 7.

These CLDs were executed on a set of 30000 chords with the algorithm (Annex B).

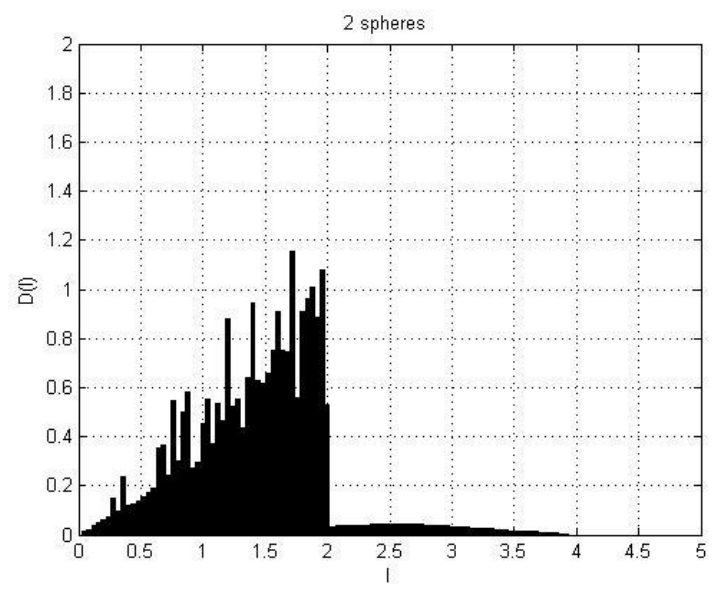

a)

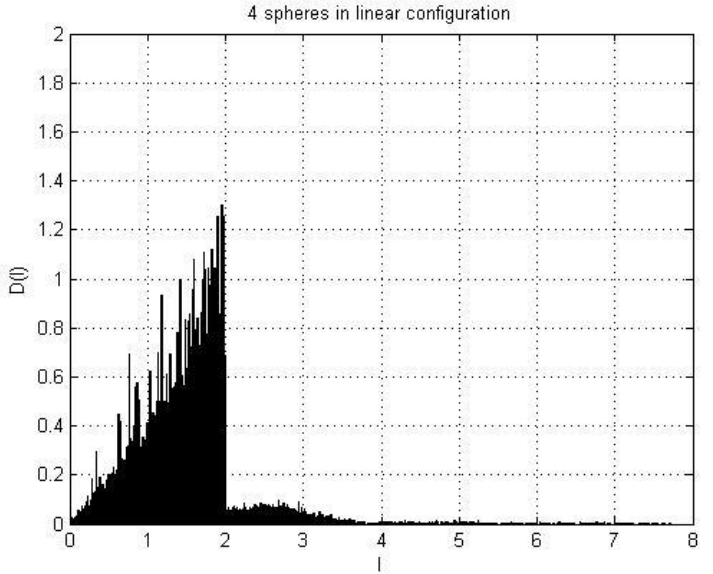

b)

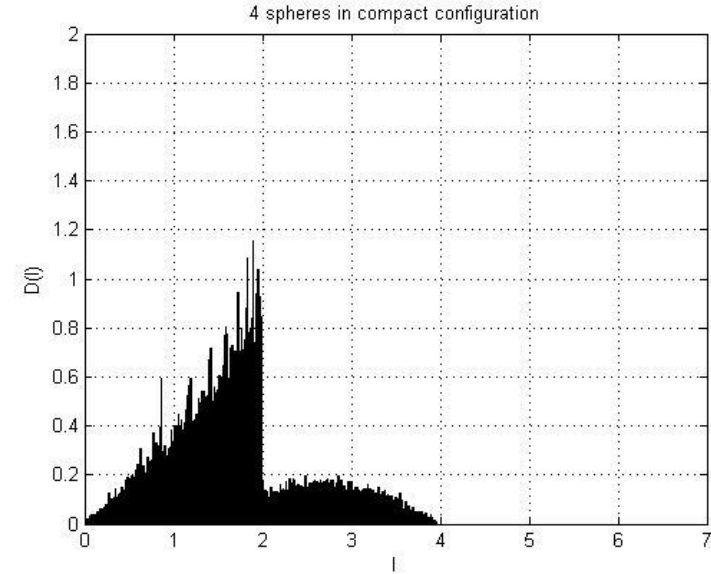

c) 


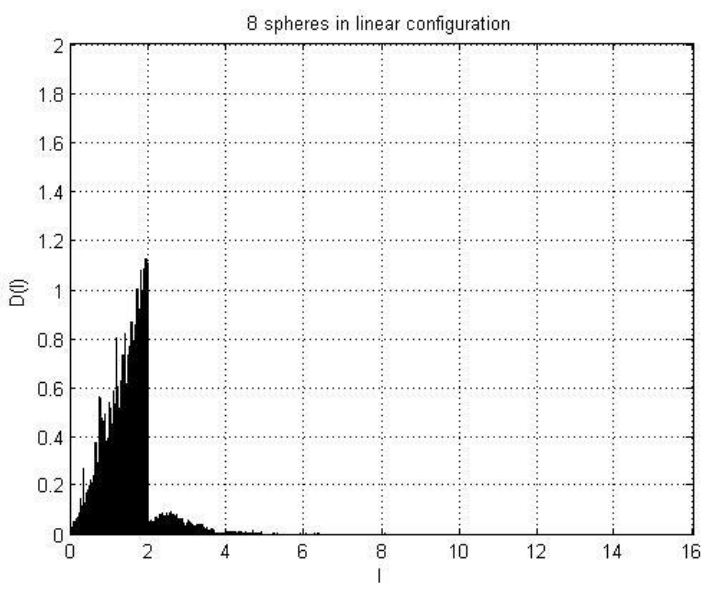

d)

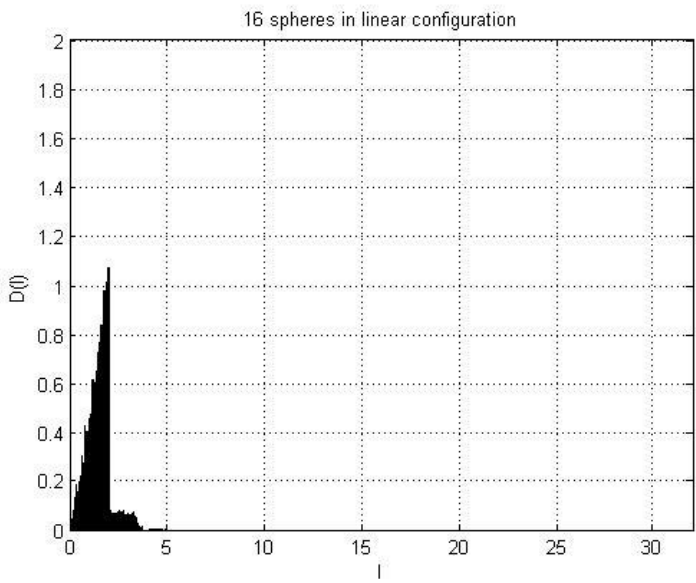

f)

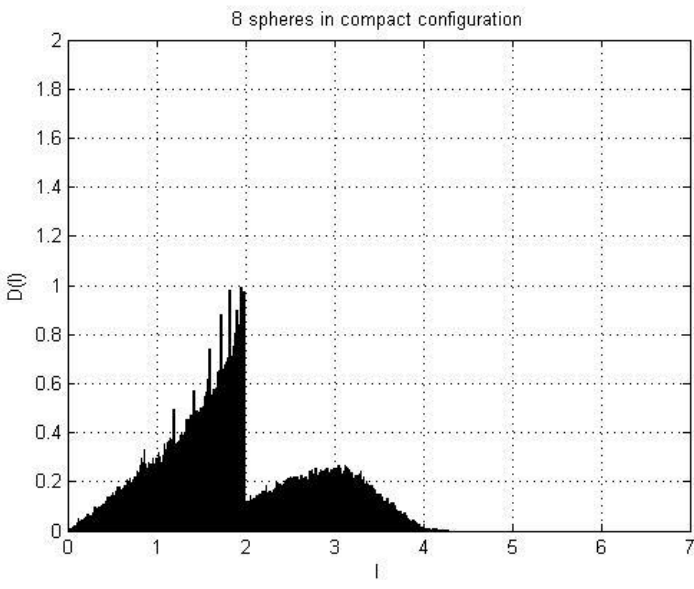

e)

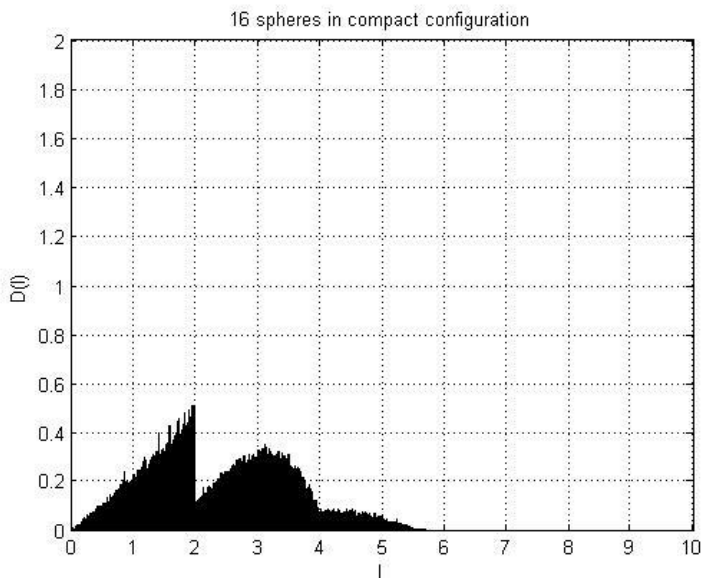

g)

Figure 5: Chord length distribution for aggregates with 2, 4, 8, 16 primary particles in linear (a,b,d,f) and compact (c,e,g)configuration.

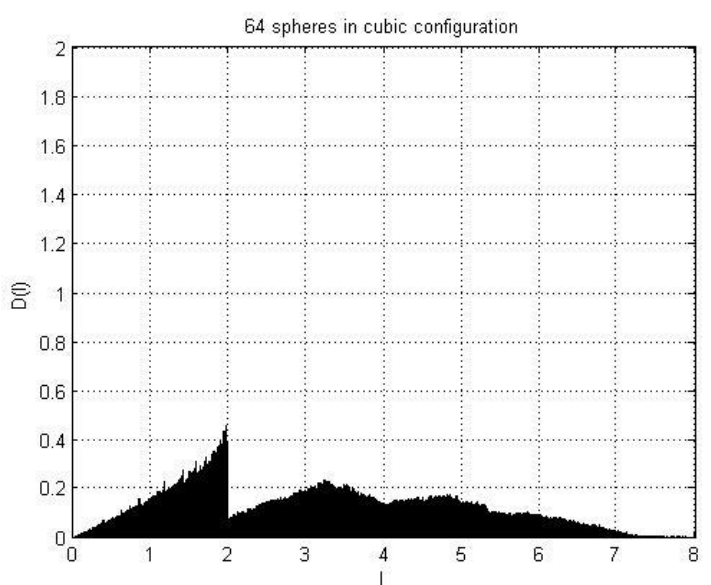

a)

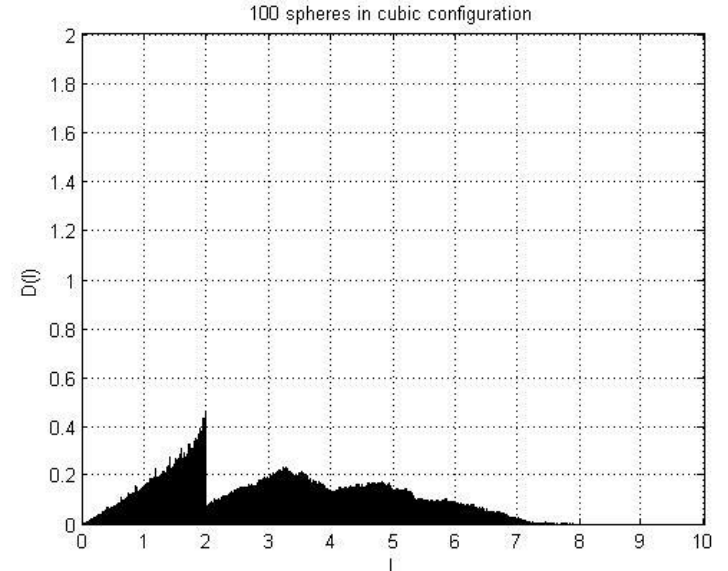

b)

Figure 6: Chord length distribution for aggregates with 64 (a) and 100 (b) primary particles in cubic configuration. 


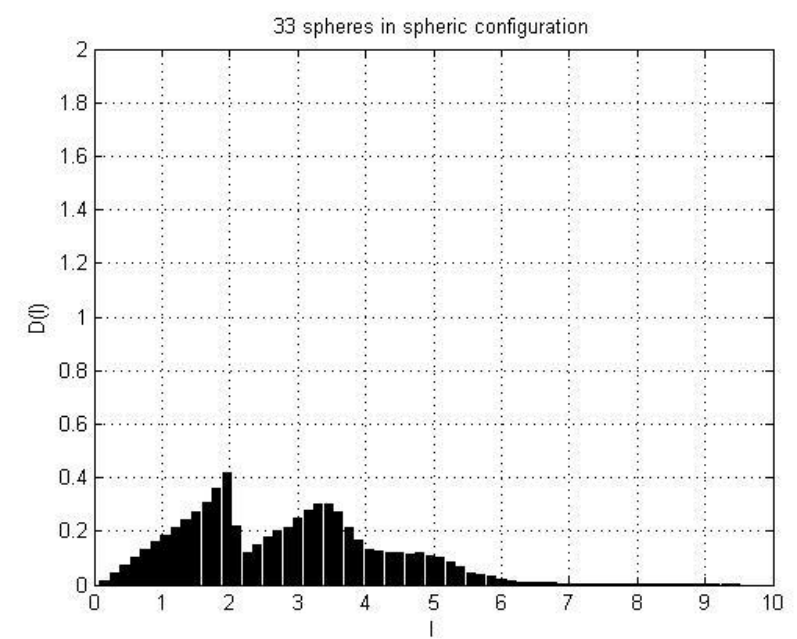

Figure 7: Chord length distribution for aggregates with 33 primary particles in spherical configuration.

It is noticeable that the chord length distribution takes into account the elementary structure of the aggregate. Indeed, whatever the aggregate configuration (cubic, planar, linear ...etc.), there appears in the first part of the chord length range a (sub) distribution similar to that of a single sphere (Figure 3 a), which constitutes the elementary structure of the considered aggregates. The second element of the distribution is a function of the general morphology of the aggregate. This second part of the distribution does not have a maximum value higher than the first. Note: the probability to obtain a chord length equal to the greatest dimension of the aggregate is almost zero percent.

\subsection{Approximated chord length distribution for aggregate}

The aggregate chord length distribution was divided into three sub-distributions. The first, which corresponds to the elementary structure (a sphere), has range of chord lengths from zero to two. The second sub-distribution, with a chord length range between 2 and 4, mainly corresponds to the structure of a doublet. The last sub-distribution lies between 4 and the maximum chord length which is specific to each aggregate. Each one of these subdistributions represents a part of the total chord length distribution; their mutual contributions are peculiar to each aggregate.

Table 2 contains the values $\left(\mathrm{x}_{1}, \mathrm{x}_{2}, \mathrm{x}_{3}\right)$ of the normalized integral $\left(x_{1}+x_{2}+x_{3}=1\right)$ of each sub-distribution for the different aggregates. 
Table $2: \mathrm{x}_{1}, \mathrm{x}_{2}$ and $\mathrm{x}_{3}$ for different aggregates.

\begin{tabular}{|c|c|c|c|c|}
\hline Configuration & $\begin{array}{c}\text { Number of } \\
\text { primary } \\
\text { particles }\end{array}$ & $\mathrm{X}_{1}$ & $\mathrm{X} 2$ & $\mathrm{X}_{3}$ \\
\hline \multirow{4}{*}{ Linear } & 2 & 0,959 & 0,0579 & 0 \\
\hline & 4 & 0,915 & 0,0758 & 0,0092 \\
\hline & 8 & 0,894 & 0,0897 & 0,0163 \\
\hline & 16 & 0,891 & 0,102 & 0,007 \\
\hline \multirow{4}{*}{ Compact } & 4 & 0,769 & 0,231 & 0 \\
\hline & 8 & 0,672 & 0,327 & 0,001 \\
\hline & 16 & 0,443 & 0,47 & 0,087 \\
\hline & 32 & 0,373 & 0,428 & 0,199 \\
\hline \multirow{4}{*}{ Plan } & 4 & 0,846 & 0,154 & 0 \\
\hline & 16 & 0,786 & 0,182 & 0,032 \\
\hline & 25 & 0,811 & 0,146 & 0,043 \\
\hline & 64 & 0,739 & 0,202 & 0,059 \\
\hline \multirow{2}{*}{ Cube } & 64 & 0,337 & 0,329 & 0,334 \\
\hline & 100 & 0,293 & 0,297 & 0,41 \\
\hline Sphere & 33 & 0,378 & 0,45 & 0,172 \\
\hline \multirow{4}{*}{ Random } & 4 & 0,87 & 0,125 & 0,005 \\
\hline & 8 & 0,833 & 0,144 & 0,023 \\
\hline & 16 & 0,725 & 0,24 & 0,035 \\
\hline & 40 & 0,6 & 0,306 & 0,094 \\
\hline
\end{tabular}

\subsubsection{Decomposition into sub distributions}

The first two sub-distributions are clearly identified. However, the last sub-distribution corresponds to the global morphology of the aggregate and is more difficult to model.

One modelling approach would be to identify this sub-distribution as being that of an equivalent sphere (in quantity of matter) to the aggregate. However, the sphere chord length distribution is an increasing function of chord length (Figure 3 a) whereas the third subdistribution decreases with the chord length. Considering this sub-distribution as a sphere leads to an erroneous distribution, especially when $\mathrm{x}_{3}$ is not negligible (eg: Figure $5 \mathrm{~g}$ ).

Another technique would be to assimilate the third sub-distribution, with a form that has an equivalent geometrical shape. Such approach implies finding, for each aggregate, an equivalent object fitting its general shape, and, to know its chord length distribution. This idea is thus exceedingly difficult to put into practice.

The simplest method would be to consider the third sub-distribution as a chord length distribution obeying:

$$
D_{3}(l)=\frac{2}{l_{\max }^{2}}\left(l_{\max }-l\right) .
$$

This corresponds to the reversed chord length distribution of the equivalent sphere in volume. This straightforward way of expressing the third sub-distribution does not have any physical basis as far as we can tell. Nevertheless, this approach makes possible to obtain the best visual fit empirically. Moreover, it possible to construct this aggregates chord length distribution simply and automatically. 
Thus the aggregate chord length distribution will be written as follows:

$D g(l)=D a(l)+D b(l)+D c(l)$

with:

- $D a(l)$ the sub-distribution attached to that of a primary sphere $D_{l}(l)$ :

$D a(l)=x_{1} D_{1}(l)$.

with: $D_{1}(l)=l / 2$

- $D b(l)$ is the sub-distribution corresponding to the doublet (two-particles set) $\mathrm{D}_{2}(l), 1$ in the range $[2,4]$ :

$$
D b(l)=x_{2} \frac{D_{2}(l \in[2,4])}{\int_{2}^{4} D_{2}(l) d l} .
$$

The chord length distribution for a doublet is analytically available:

$$
\begin{aligned}
D_{2}(l \in[2,4])= & \frac{1}{16\left(1+\frac{8}{3 \pi}\right)} \\
& {\left[l \frac{16-l^{2}}{16+l^{2}}+\frac{3 l^{2}-16}{8}\left(\arcsin \left(\left(1+\frac{l^{2}}{16}\right)^{-1 / 2}\right)-\arcsin \left(\frac{l}{4}\left(1+\frac{l^{2}}{16}\right)^{-1 / 2}\right)\right)\right] }
\end{aligned}
$$

- $D c(l)$ is the contribution of the chord length distribution of the equivalent object for aggregate (10). This method limits the maximum chord length to $l_{\max }=2 N^{1 / 3}$ with $\mathrm{N}$ the number of primary particles within the considered aggregate. This leads thus to:

$$
D c(l)=x_{3} \frac{D_{3}\left(l \in\left[4, l_{\max }\right]\right)}{\int_{4}^{l_{\max }} D_{3}(l) d l}
$$

\subsubsection{Relations for $x_{1}, x_{2}, x_{3}$ and $\left\langle S_{p} \geq\right.$}

In order to complete the aggregates CLD description, we need to express $\mathrm{x}_{1}, \mathrm{x}_{2}, \mathrm{x}_{3}$ and $\left\langle\mathrm{S}_{\mathrm{p}}\right\rangle$ according to parameters which consider the aggregate morphology. For that, we suggest expressing them according to both the number $\mathrm{N}$ of primary particles and the morphological parameter $d_{1}$ which is defined as the average distance between primary particles in the aggregate:

$$
d_{1}=\frac{1}{N(N-1)} \sum_{i, j} d_{i, j}
$$


$d_{i, j}$ is the centre-centre distance between $\mathrm{i}$ and $\mathrm{j}$ particles. This parameter $d_{i, j}$ is dimensionless.

$-\underline{\mathrm{x}}_{1}, \mathrm{x}_{2}, \mathrm{X}_{3}$

Figure 8 represents the change of $\mathrm{x}_{3}$, according to $\mathrm{N}$ and $\mathrm{d}_{1}$, for 19 aggregates (Table 2).

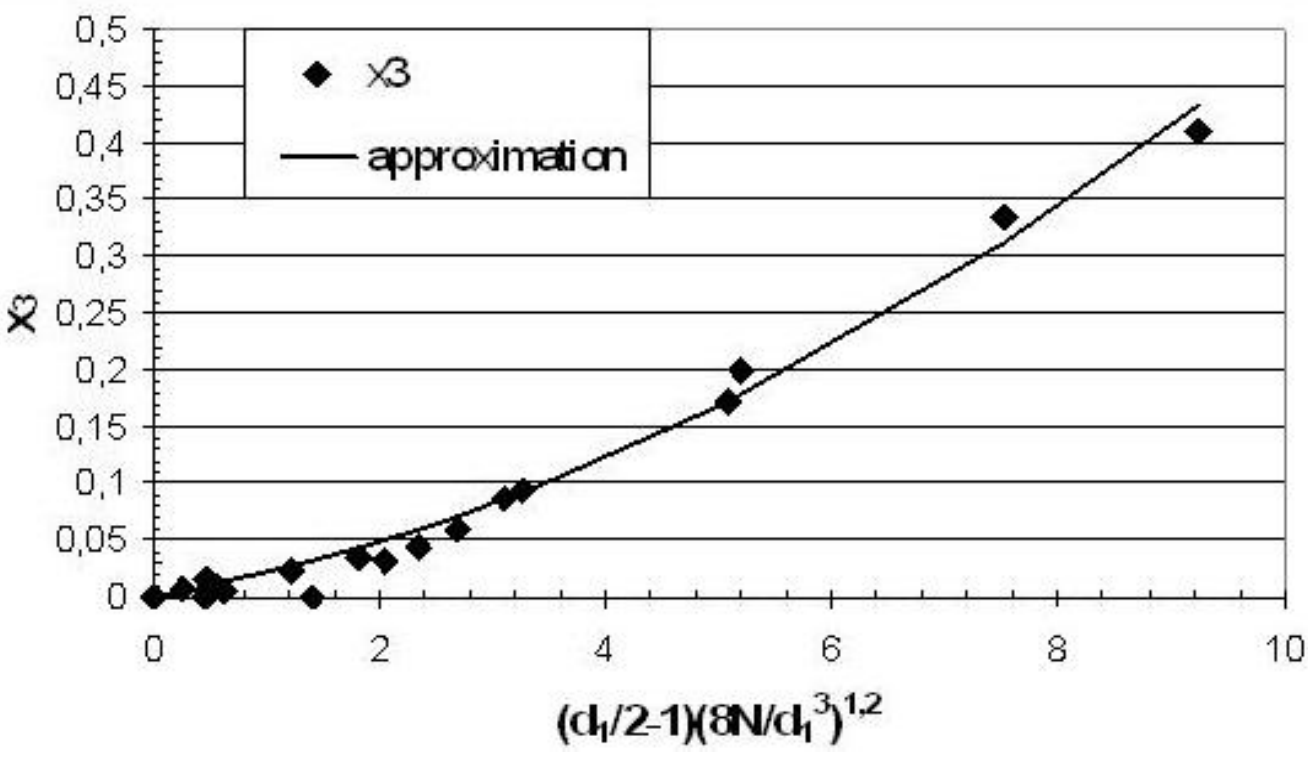

Figure 8: $x_{3}$ according to the number of primary particles $N$ and the average inter particle distance $d_{1}$.

Following this representation, $\mathrm{x}_{3}$ is defined as follows:

$$
x_{3}=0.0031 \beta^{2}+0.0182 \beta \text { with } \beta=\left(\frac{d_{1}}{2}-1\right)\left(\frac{N}{\left(d_{1} / 2\right)^{3}}\right)^{1.2}
$$

The term $N /\left(d_{1} / 2\right)^{3}$ characterizes the compactness of the aggregate. The term $\left(\frac{d_{1}}{2}-1\right)$ shows that only large aggregates have high $\mathrm{x}_{3}$ values.

We express the ratio $\mathrm{x}_{2} / \mathrm{x}_{1}$ instead of $\mathrm{x}_{2}$ or $\mathrm{x}_{1}$, because $\mathrm{x}_{2} / \mathrm{x}_{1}$ is easier to link to $\mathrm{N}$ and $\mathrm{d}_{1}$. Thus the Figure 9 represents the change of $\mathrm{x}_{2} / \mathrm{x}_{1}$ according to $\mathrm{N}$ and $\mathrm{d}_{1}$. 


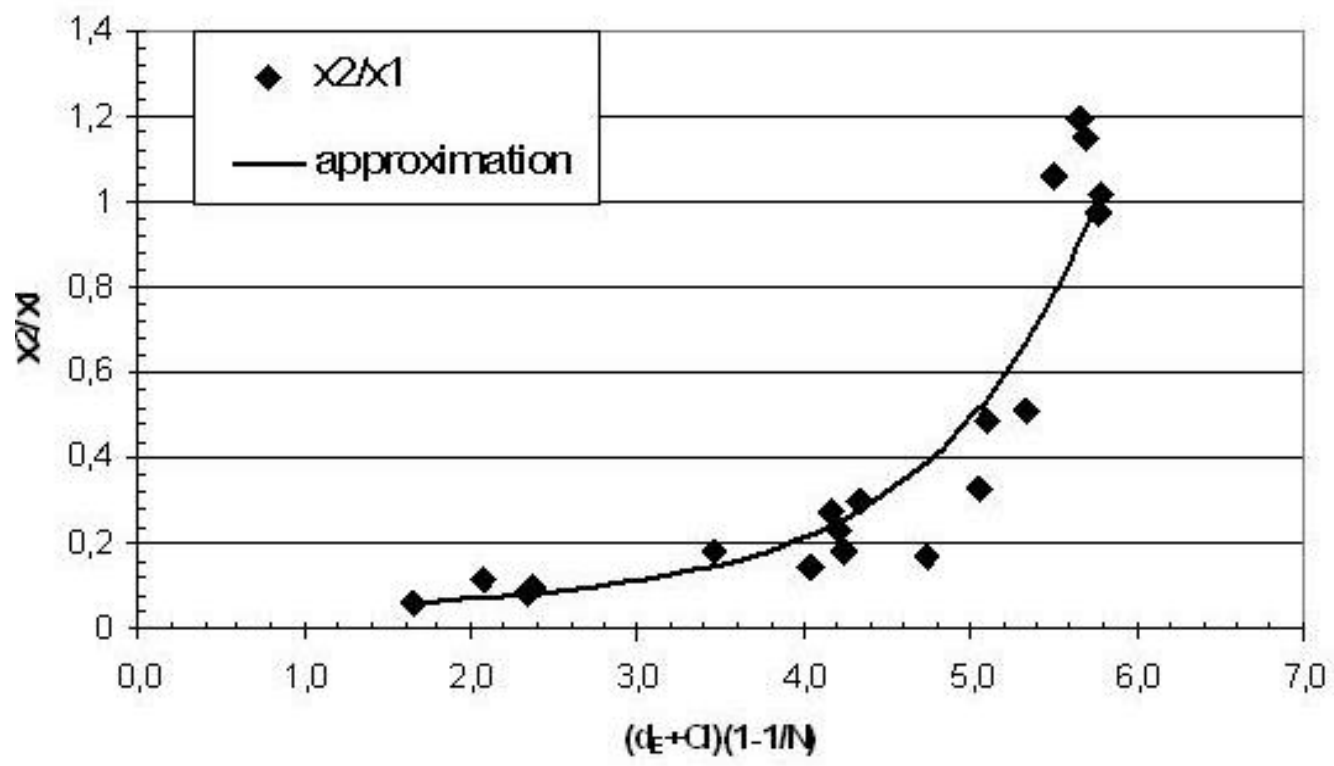

Figure 9: Evaluation of $\mathrm{x}_{2} / \mathrm{x}_{1}$ according to the number of primary particles $\mathrm{N}$ and the average inter particle distance $\mathrm{d}_{1}$.

The relevant morphological parameter is

$$
\begin{aligned}
& \left(d_{E}+C I\right)\left(1-N^{-1}\right) \\
& -C I \text { is a compactness index defined by } \\
& \quad C I=3+\log \left((N-1) / 5 d_{1}^{3}\right) \\
& -\mathrm{d}_{\mathrm{E}} \text { is the aggregate space dimension (linear: } \mathrm{d}_{\mathrm{E}}=1 \text {, plan: } \mathrm{d}_{\mathrm{E}}=2 \text {, compact: } \mathrm{d}_{\mathrm{E}} \\
& \quad=3)
\end{aligned}
$$

The higher $C I$ is, the higher the compactness is.

Thus, with an average error of $26 \%$ :

$$
x_{2} / x_{1}=0.96\left(\frac{1}{320} \exp \left(\left(d_{E}+C I\right)\left(1-N^{-1}\right)\right)+0.05\right)
$$

Knowing $\mathrm{x}_{3}$ and $\mathrm{x}_{2} / \mathrm{x}_{1}$ we deduce $\mathrm{x}_{2}$ with an average error of $19 \%$ and $x_{1}=1-x_{2}-x_{3}$ with an average error of $6.6 \%$.

\section{- Average projected area $\langle\mathrm{Sp}\rangle$}

We also calculated the average projected area for different configurations and expressed it by the following function:

$$
<S_{p}>=1.25 \pi\left(\left(\frac{d_{1}}{2}\right)^{1 / 3} N^{1 / 3}\right)^{1.25}
$$

The average error relative to this expression is around $5 \%$.

The use of expressions for $\left\langle\mathrm{S}_{\mathrm{p}}\right\rangle, \mathrm{x}_{1}, \mathrm{x}_{2}$ and $\mathrm{x}_{3}$ leads to having an analytical equation for the CLD of aggregates. 


\subsubsection{Approximated CLD}

Figure 10 and Figure 11 compare the CLD resulting from numerical simulations for the chosen aggregates to those obtained using our predefined sub-distributions (the $\mathrm{x}_{1}, \mathrm{x}_{2}, \mathrm{x}_{3}$ values are exactly those of Table 2). The following Figure 10 corresponds to the well ordered aggregates.

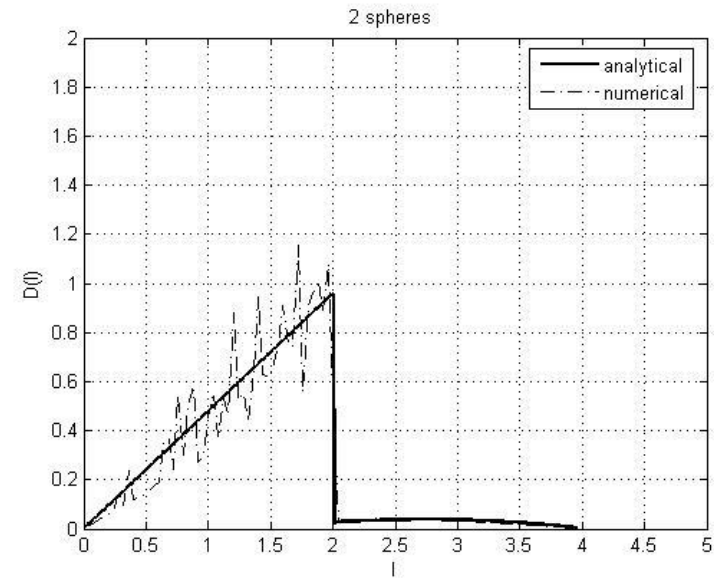

a)

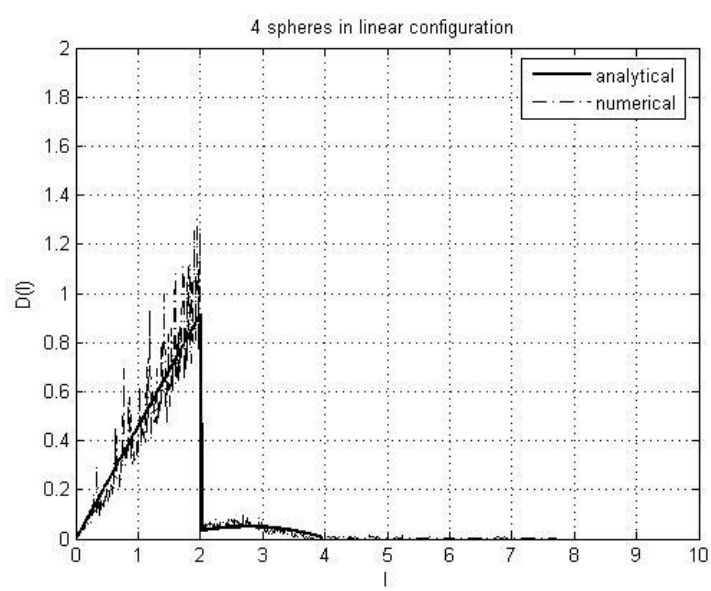

b)

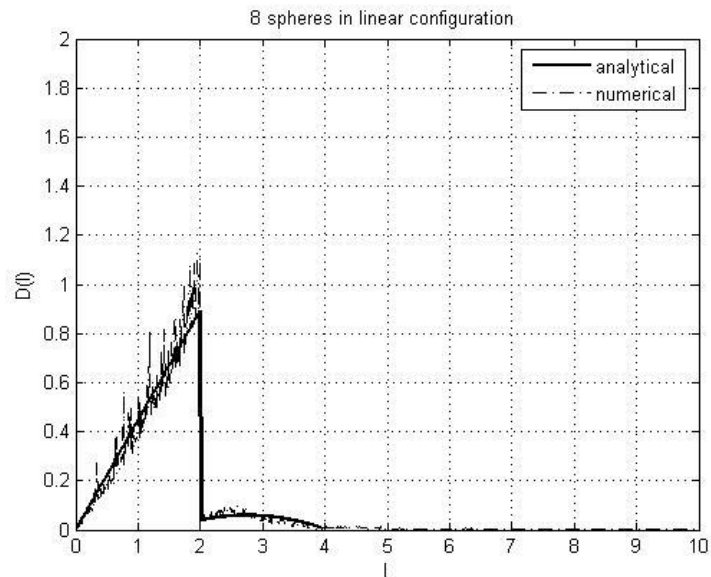

d)

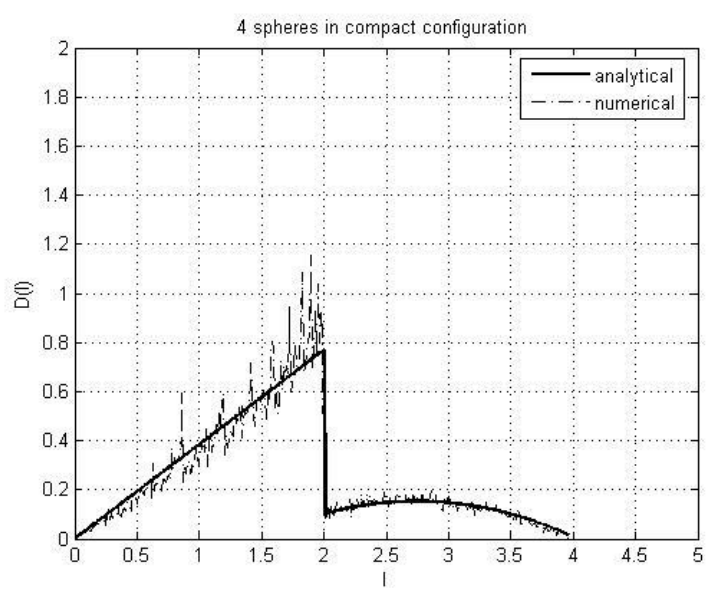

c)

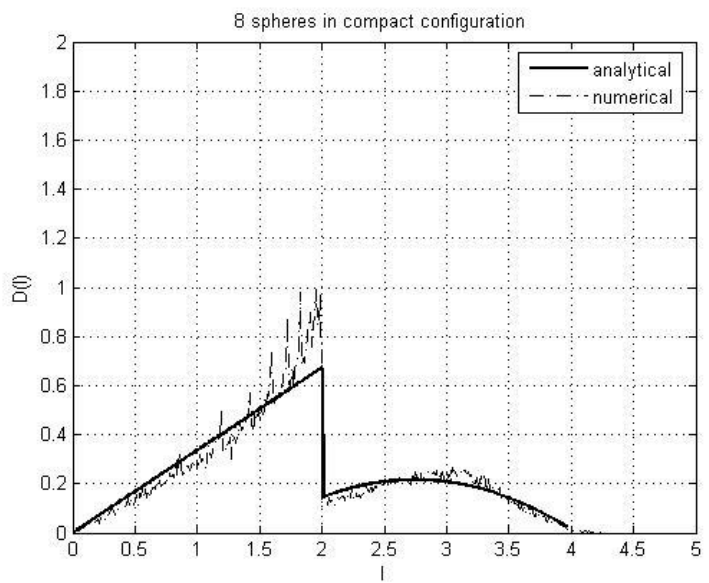

e) 


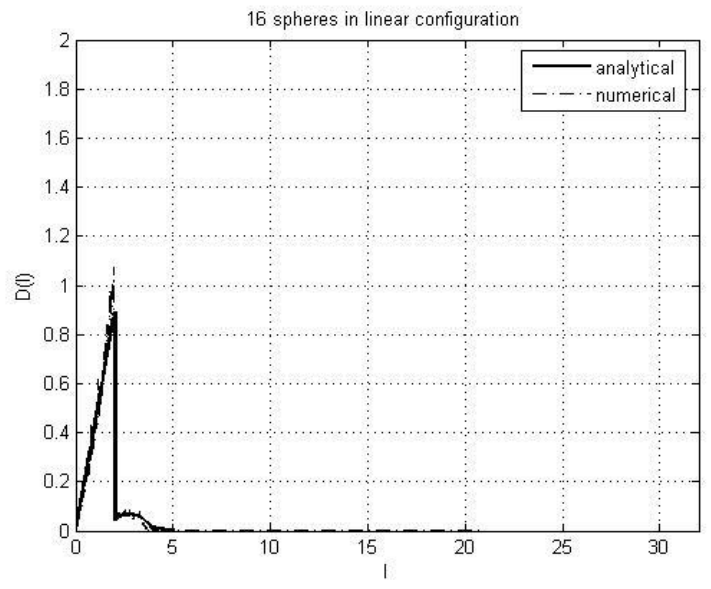

f)

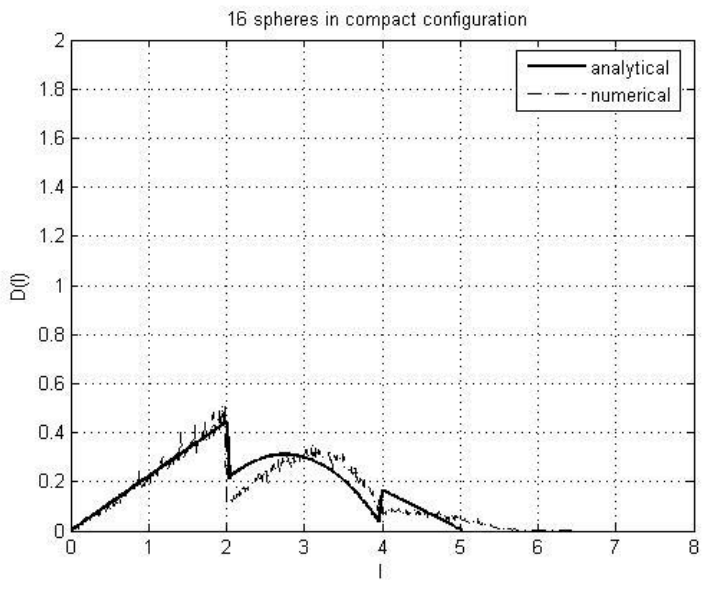

g)

Figure 10: Comparison between CLD resulting from numerical simulations and those rebuilt with the subdistributions (analytical)), for aggregates with 2, 4, 8 and 16 primary particles in linear (a,b,d,f) and compact $(\mathrm{c}, \mathrm{e}, \mathrm{g})$ configurations.

The following Figure 11a,b,c,d correspond to the random aggregates.

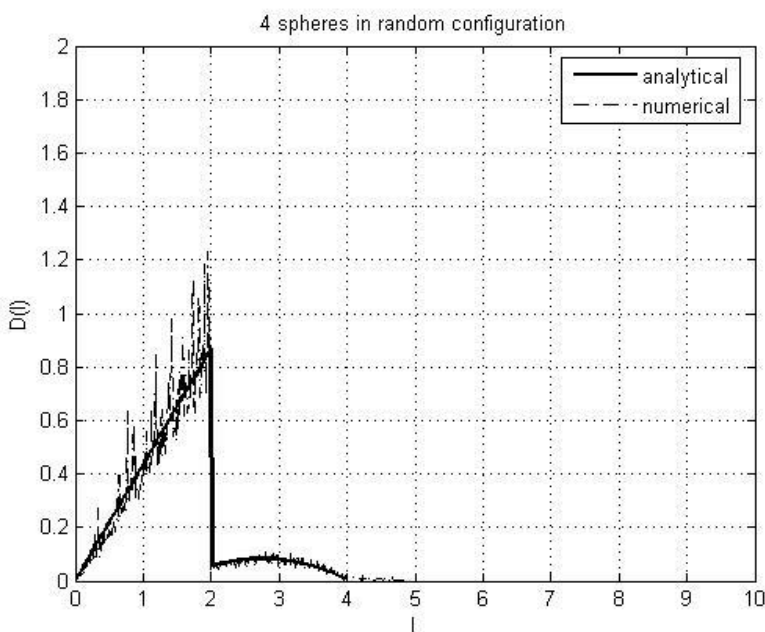

a)

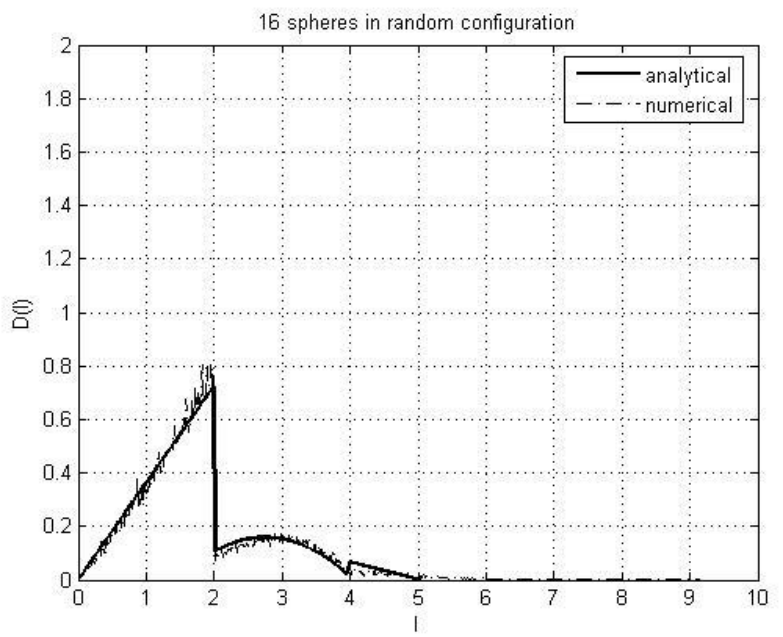

c)

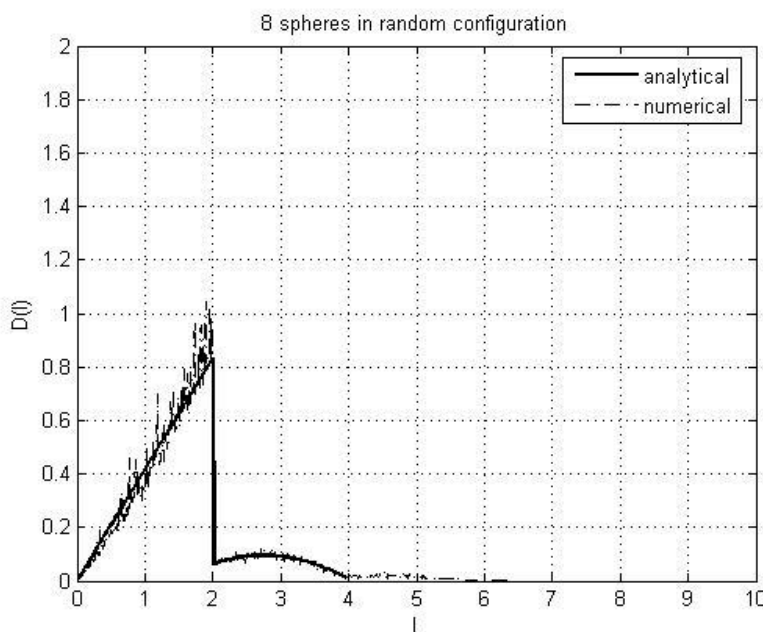

b)

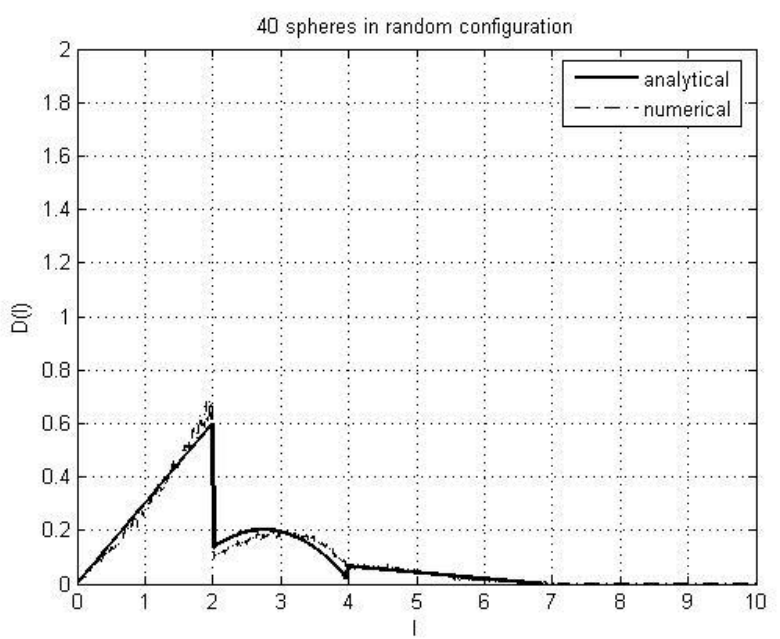

d) 
Figure 11 : Comparison between the CLD resulting from numerical simulations and those rebuilt with the subdistributions (analytical), for aggregates with 4, 8, 16 and 40 primary particles in random configuration.

We conclude that the way to analytically represent the chord length distribution for an aggregate is not perfect but is a satisfactory approximation. So, in the next section we will compare the scattering cross section values obtained with the exact method (GMM), anomalous diffraction AD approximation (5) and anomalous diffraction which uses the chord length distribution in its formulation $\operatorname{ADr}((7)$ and (11)).

\section{Aggregate scattering cross section with the AD method}

We studied aggregates with $\mathrm{N}$ primary particles in the range $[2,100]$. The size parameter of primary particles is in the range [2, 9.25]. For each $\mathrm{N}$-aggregate, several morphologies or compactness: linear, plan, compact, random configuration were considered. Each material is considered non-absorbent i.e. the imaginary part of the relative refractive index is equal to zero $(\operatorname{Im}(m)=0)$, with low $\left(\mathrm{SiO}_{2}, \mathrm{~m}=1.08\right)$ and intermediate $\left(\mathrm{Al}_{2} \mathrm{O}_{3}, \mathrm{~m}=1.32\right)$ optical contrast in water.

In order to compare the approximated methods ( $\mathrm{AD}$ and $\mathrm{ADr}$ ), the ratio $\mathrm{R}$ which is defined as the ratio of the aggregate scattering cross section obtained with the ADr method, and $\mathrm{AD}$ method was evaluated.

$$
R=\frac{C_{A D r, N}}{C_{A D, N}}
$$

The table 3 contains the comparison of ADr to AD, with the mean value of $\mathrm{R}$ (over $100 \mathrm{x}$ values) and the relative standard deviation $(\sigma)$ between ADr and AD .

Two extreme configurations (linear and compact) and the random configuration for $\mathrm{SiO}_{2}$ material are presented below.

Table 3: Comparison between $\mathrm{AD} \& \mathrm{ADr}$ for $\mathrm{SiO}_{2}$ with the primary particle size range $x \in[2,10]$ and different cluster type.

\begin{tabular}{|c|l|c|c|c|}
\cline { 3 - 5 } \multicolumn{2}{c|}{} & linear configuration & compact configuration & random configuration \\
\hline \multirow{2}{*}{$\mathrm{R}$} & mean & 0,97 & 0,97 & 0,95 \\
\cline { 2 - 5 } & $\sigma$ & 0,05 & 0,04 & 0,08 \\
\hline
\end{tabular}

The mean value of $\mathrm{R}$ is close to 1 no matter what the configuration. The deviation between $\mathrm{AD}$ and $\mathrm{ADr}$ seems to be smaller than $5 \%$.

The scattering cross section computation times are a function of: the primary particle size parameter, number of primary particle in the aggregate and shape of the aggregate. Table 4 gives an example of this. Since scattering cross section computation times entail many parameters their times can be excessive. However, ADr computation times are always the same. Given that the ADr computation times are less than those of AD a least a factor 100, our method proves to be extremely advantageous. 
Table 4: CPU time for $\mathrm{AD}$ and ADr methods obtained with AMD Athlon 64 processor 3500, 2.23Ghz, $1 \mathrm{G}$.

\begin{tabular}{|l|c|c|c|c|}
\cline { 2 - 5 } \multicolumn{1}{c|}{} & \multicolumn{2}{c|}{$\mathrm{x}=3.96$} & \multicolumn{2}{c|}{$\mathrm{x}=9.91$} \\
\cline { 2 - 5 } \multicolumn{1}{c|}{} & $\mathrm{AD}$ & $\mathrm{ADr}$ & $\mathrm{AD}$ & $\mathrm{ADr}$ \\
\hline 16 spheres in compact configuration & $47.3 \mathrm{~s}$ & $0.05 \mathrm{~s}$ & $49.2 \mathrm{~s}$ & $0.05 \mathrm{~s}$ \\
\hline 64 spheres in cubic configuration & $259.5 \mathrm{~s}$ & $0.05 \mathrm{~s}$ & $280.4 \mathrm{~s}$ & $0.05 \mathrm{~s}$ \\
\hline
\end{tabular}

Now the scattering cross section will be evaluated by comparing the values obtained with $\mathrm{AD}$ and $\mathrm{ADr}$ with those resulting from the exact method.

The term, exact method, indicates that the results are obtained with the GMM computer code developed by Y-L. Xu. We compare the scattering cross section obtained with the approximated method to that of the exact method by means of the ratio $\mathrm{R}_{\mathrm{m}}$ defined by:

$$
R_{m}=\frac{C_{m e t h o d, N}}{C_{X u, N}}
$$

An illustration of the effect of the change of size parameters for ratio $\mathrm{R}_{\mathrm{m}}$ can be found in the following figure 12 .

As expected, the $\mathrm{AD}$ method is unsuited to the small size parameters but proves to be adequate approximation for a size parameter higher than 2. The deviation between ADr and the exact method is smaller than $15 \%$ for primary particle size parameters larger than 2 . It is important to recall that the AD method is strongly related to the configuration (morphology) since it includes in its formulation the chord length distribution of the aggregate.

The approximated methods AD and ADr (Figure 12) lead to qualitatively and quasi quantitatively identical curves whatever the configuration. But the results obtained with ADr are not as close to the exact method as AD is. According to the analysis of the curves, this weakness in ADr method is observed for configurations where the approximated third chord length sub-distribution is imperfect.

The same study was performed for $\mathrm{Al}_{2} \mathrm{O}_{3}$ material. The results are presented in Annex D. The optical refractive index is far from the validity range within which the AD method can be applied. However this study shows that ADr results are similar to AD. 
AD

ADr

Linear configuration

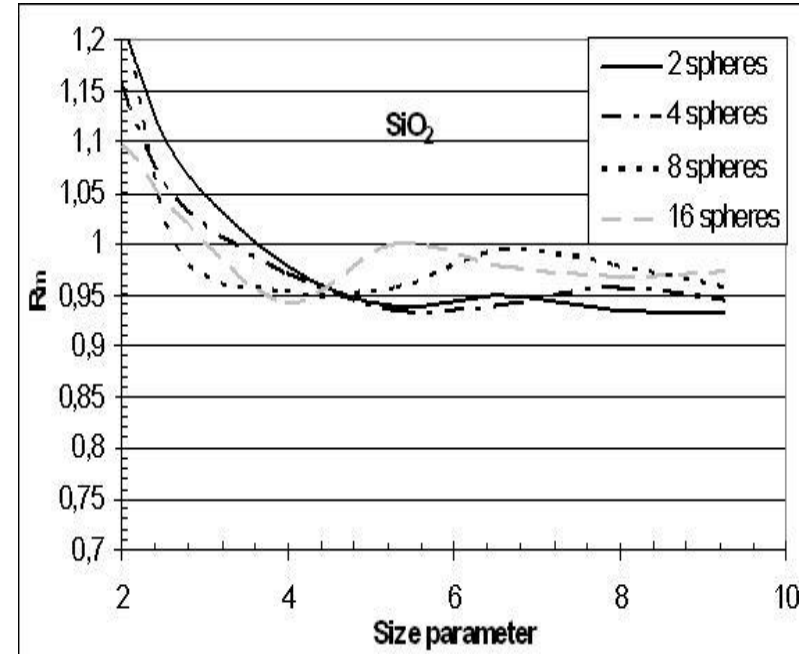

a)

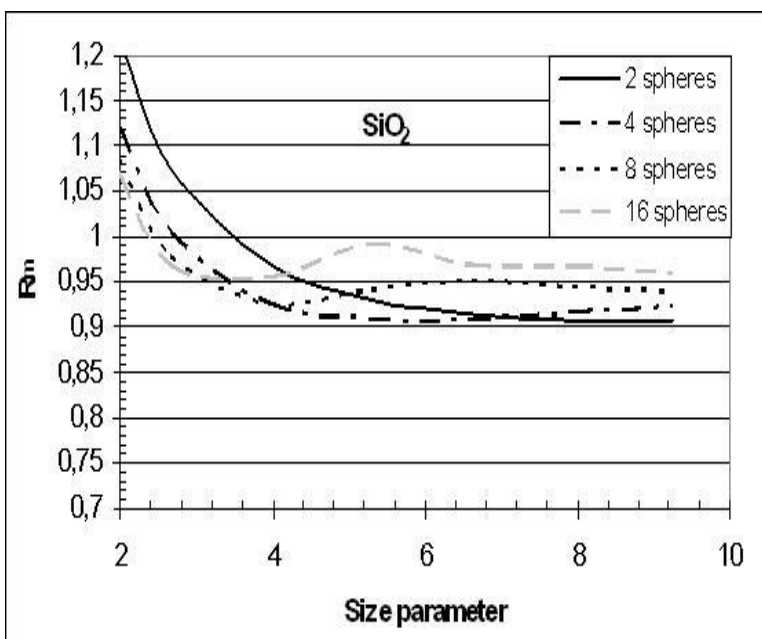

b)

Compact configuration

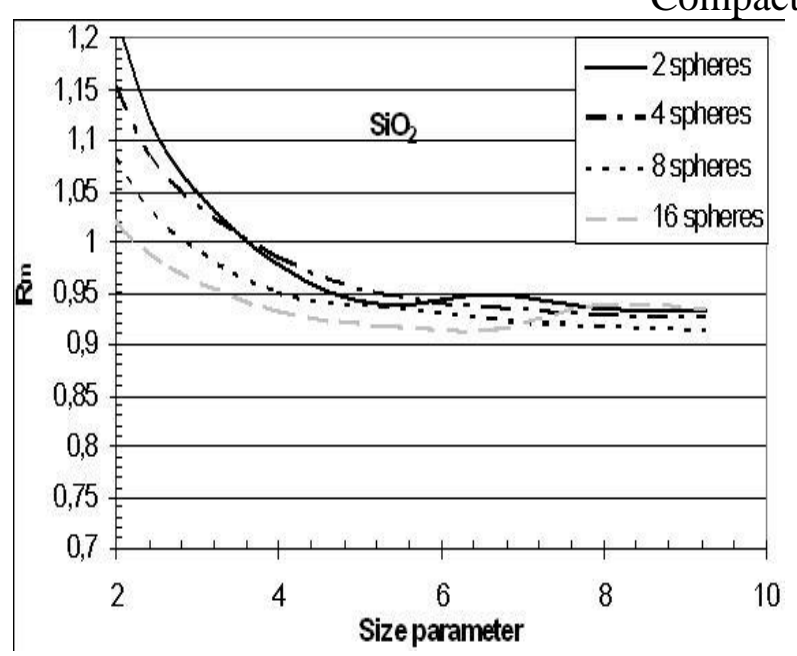

c)

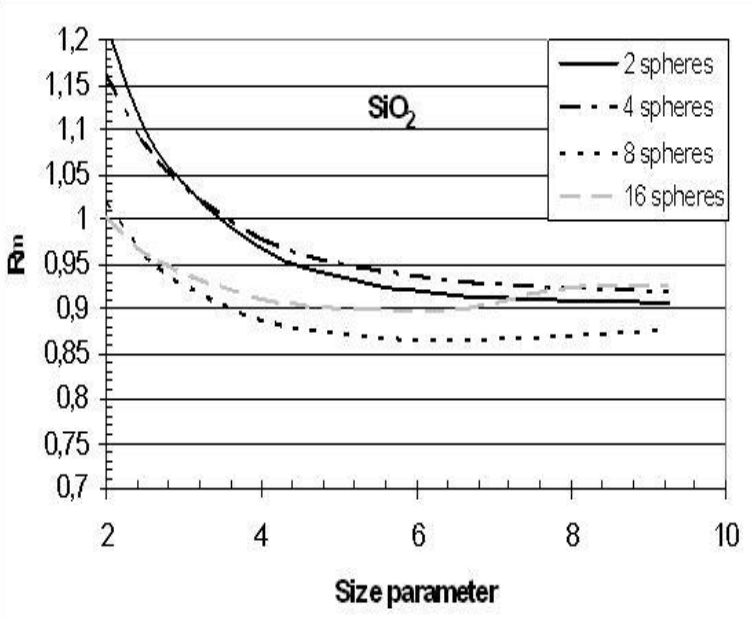

d)

Random configuration

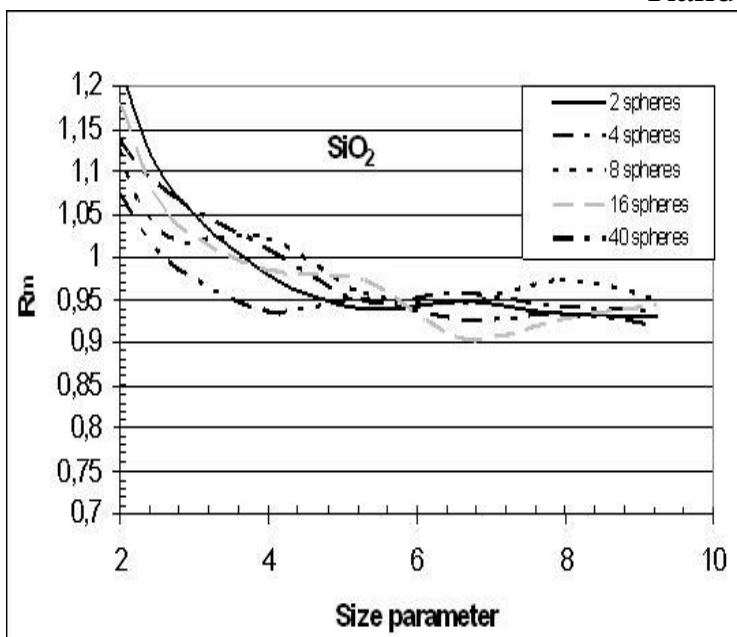

e)

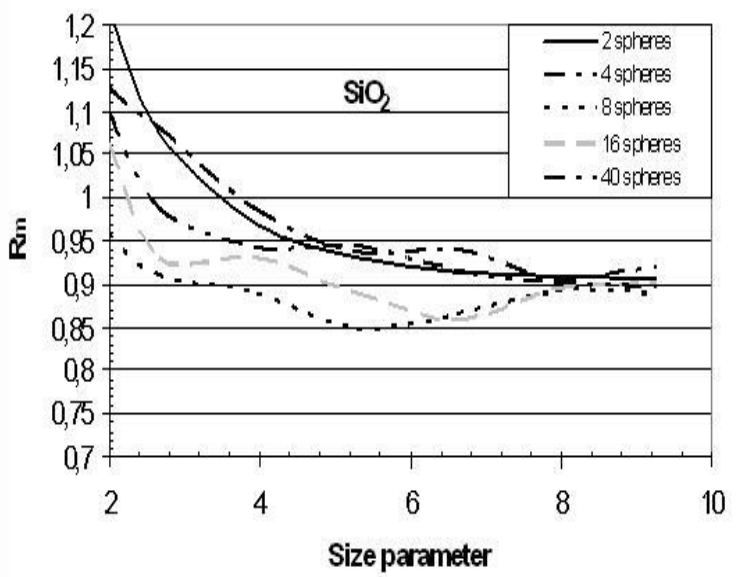

f)

Figure 12: $\mathrm{AD}\left(1^{\text {st }}\right.$ column $)$ and $\mathrm{ADr}\left(2^{\text {nd }}\right.$ column $)$ methods with $R_{m} \in[0.7,1.2]$ as a function of the primary particle size parameter, for $\mathrm{SiO}_{2}$ and 3 configurations: linear ( $1^{\text {st }}$ row), compact ( $2^{\text {nd }}$ row) and random ( ${ }^{\text {rd }}$ row). 
The ADr method was also evaluated when $\mathrm{x}_{1}, \mathrm{x}_{2}, \mathrm{x}_{3}$ and $\left\langle\mathrm{S}_{\mathrm{p}}\right\rangle$ are defined as presented in the paragraph 3.3.2.

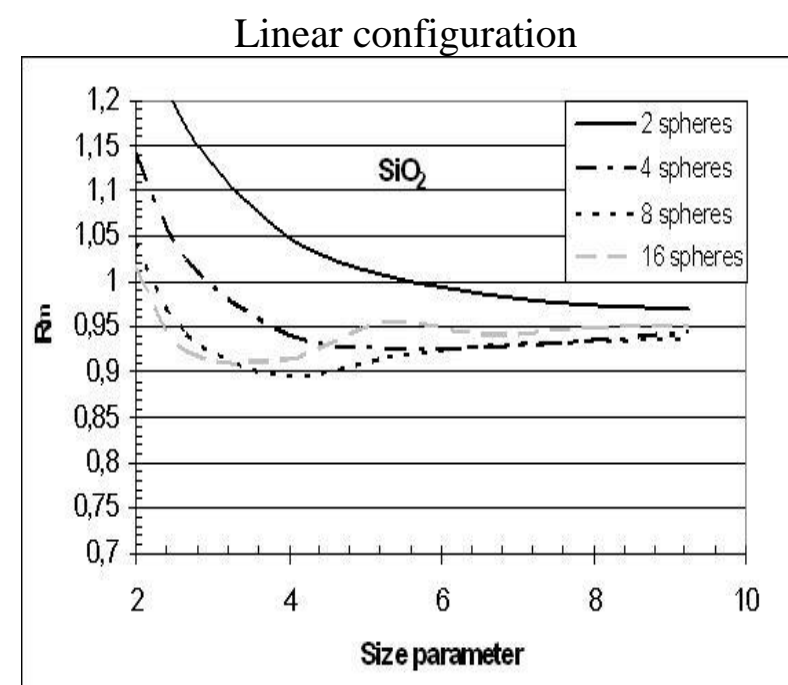

a)

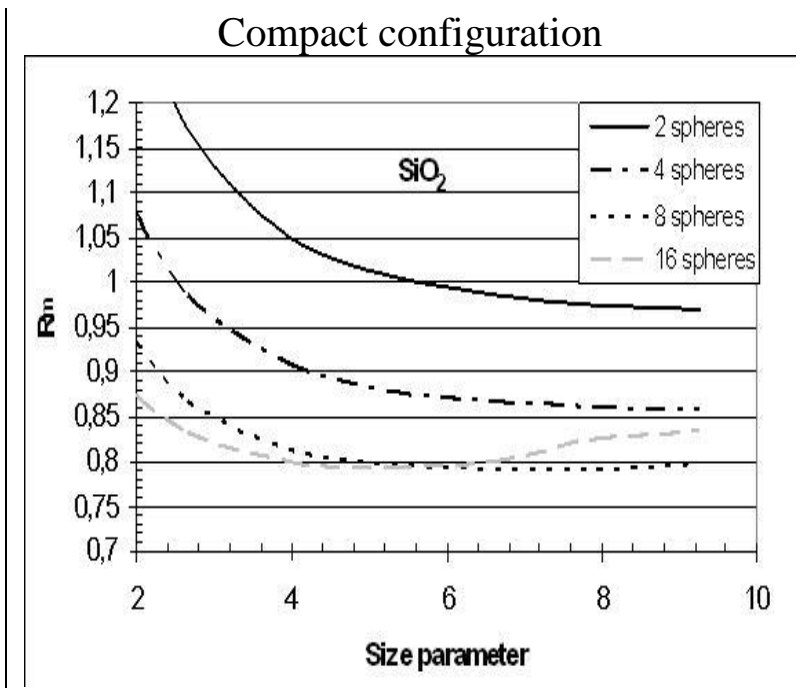

b)

Figure 13: ADr method with analytical $\mathrm{x}_{1}, \mathrm{x}_{2}, \mathrm{x}_{3},\left\langle\mathrm{~S}_{\mathrm{p}}\right\rangle$ as a function of the size parameter, for $\mathrm{SiO}_{2}$ material and 2 configurations : linear ( $1^{\text {st }}$ column $)$ and compact $\left(2^{\text {nd }}\right.$ column $)$.

When we use $\mathrm{x}_{1}, \mathrm{x}_{2}, \mathrm{x}_{3}$ and $\left\langle\mathrm{S}_{\mathrm{p}}\right\rangle$, such as they are defined in the previous section, there is a loss of accuracy which is a function of the aggregate configuration and the number of primary particles in it. In order to improve the analytical method, it will be necessary to reexamine the empirical expressions for these four parameters.

\section{Conclusion}

Although the Anomalous Diffraction method is valid only for soft material, this approach was tested not only for $\mathrm{SiO}_{2}$ in water, but also for $\mathrm{Al}_{2} \mathrm{O}_{3}$ as well.

Since chord length is the relevant variable, the AD method was reformulated according to the chord length distribution: ADr

On the basis of the assessment that the aggregate chord length distribution is not analytically accessible this was studied. In conclusion:

- $\quad$ chord length distribution clearly shows the fine structure of the aggregate,

- $\quad$ aggregate chord length distribution may be broken up into three sub-distributions. Each one of these sub-distributions represents a part of the whole distribution, with their contribution peculiar to each aggregate,

proportions of these sub-distributions were expressed according to parameters connected to the aggregate morphology (number of primary particles $\mathrm{N}$ within the aggregate and the average inter-particle distance $\mathrm{d}_{1}$ ), 
The comparison of the AD and ADr methods shows that: the introduction of the chord length distribution is fertile ground for study. The developed ADr method gives the same results as $\mathrm{AD}$ with an error rate of around plus or minus 5\%. The use of empirical equations for $\mathrm{x}_{1}, \mathrm{x}_{2}, \mathrm{x}_{3},\left\langle\mathrm{~S}_{\mathrm{p}}\right\rangle$ offers the possiblility to formulate analytically the Anomalous Diffraction method. This decreases the computing times by at least a factor of 100 . Unfortunately, ADr does diverge slightly from the exact method than AD.

In order to diminish this small discrepancy between $\mathrm{AD}$ and $\mathrm{ADr}$, future work must be done on the manner of expressing both: the third sub-distribution representation and $\mathrm{x}_{1}, \mathrm{x}_{2}, \mathrm{x}_{3}$, $\left\langle\mathrm{S}_{\mathrm{p}}\right\rangle$ functions analytically. Work is already in planning, in part, to resolve this problem by increasing the studied number of aggregates in order to develop more precise laws for $\mathrm{x}_{1}, \mathrm{x}_{2}$, $\mathrm{x}_{3}$. 


\section{Appendix:}

\section{A. Expression for the chord length distribution of a spheroid}

In this appendix, different lengths are kept with their dimensions.

A prolate or an oblate spheroid is considered: $x^{2} / a^{2}+y^{2} / b^{2}+z^{2} / b^{2}=1$

The spheroid projection on an unspecified plan was examined. This is equivalent to examining the projection of a tilted spheroid on the plan $(\mathrm{x}, \mathrm{z})$. The angle between the semiaxis $a$ and the plan $(\mathrm{x}, \mathrm{z})$ is denoted by $\theta$.

$S_{c}$ is the area of the ellipse, which is the locus of constant chord length $l$.

The ratio between $S_{c}$ and the projected area $S_{p}$ represents the chord fraction of which the length is greater than $l$.

$$
S_{c} / S_{p}=\left(1-C l^{2} / 4\right) \text { with } C=\sin ^{2} \theta / a^{2}+\cos ^{2} \theta / b^{2}
$$

Thus, chord length density is:

$$
\begin{aligned}
& D(l, \theta)=\left|d S_{c} / S_{p} / d l\right|=C l / 2 \\
& \text { with } \int_{0}^{2 / \sqrt{C}} D(l) d l=1
\end{aligned}
$$

- if $\mathrm{a}<\mathrm{b} ; \mathrm{C}$ is an increasing function of $\theta$

The probability $\mathrm{P}$ that the chord length (noted $\mathrm{h}$ ) is greater than a given value (noted $\mathrm{l}$ ) is equal to:

$$
P(h>l)=\frac{\int_{0}^{\theta_{N}(l)} S_{c}(h>l, \theta) \cos \theta d \theta}{\int_{0}^{\pi / 2} S_{p}(\theta) \cos \theta d \theta}
$$

$\theta_{N}$ is such as: $S_{c}\left(l, \theta_{N}\right)=0$, i.e. $C\left(\theta_{N}\right)=4 / l^{2}$

We deduce from $\mathrm{P}, D(l)$, which is the derivative of $P(h>l)$ compared to $\mathrm{l}$ :

$$
D(l)=\frac{l}{2} \frac{\int_{0}^{\theta_{N}(l)} S_{p}(\theta) C \cos \theta d \theta}{\int_{0}^{\pi / 2} S_{p}(\theta) \cos \theta d \theta}
$$

- if $\mathrm{a}>\mathrm{b}, D(l)=\frac{l}{2} \frac{\int_{\theta_{N}(l)}^{\pi / 2} S_{p}(\theta) C \cos \theta d \theta}{\int_{0}^{\pi / 2} S_{p}(\theta) \cos \theta d \theta}$

The average projected area obeys: $\left\langle S_{p}>=\int_{0}^{\pi / 2} S_{p}(\theta) \cos \theta d \theta\right.$

by denoting $h_{N}=\sin \theta_{N}, U=\left(\left(b^{2} / a^{2}\right)-1\right)^{1 / 2}, V=\left(1-\left(b^{2} / a^{2}\right)\right)^{1 / 2}$, one obtains :

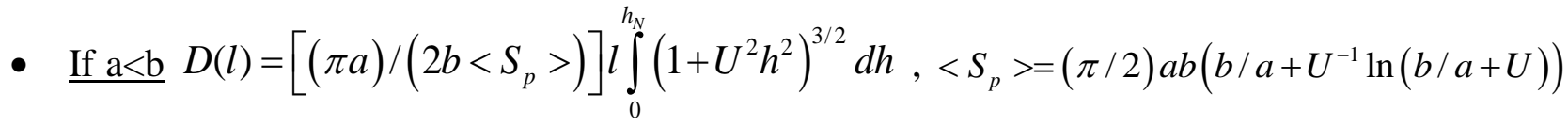


then :

- if $l>2 a$

$D(l)=\left[(\pi a) /\left(16 b<S_{p}>U\right)\right] l\left[\begin{array}{c}\left((2 b / l)^{2}-1\right)^{1 / 2} 2 b / l\left(3+8 b^{2} / l^{2}\right) \\ +4 \ln \left(2 b / l+\left((2 b / l)^{2}-1\right)^{1 / 2}\right)+\ln \left(2 b / l-\left((2 b / l)^{2}-1\right)^{1 / 2}\right)\end{array}\right]$

- if $l<2 a$

$D(l)=\left[(\pi a) /\left(16 b<S_{p}>U\right)\right] l\left[U\left(U^{2}+1\right)^{1 / 2}\left(5+2 U^{2}\right)+4 \ln \left(U+\left(U^{2}+1\right)^{1 / 2}\right)+\ln \left(\left(U^{2}+1\right)^{1 / 2}-U\right)\right]$

- If $\mathrm{a}>\mathrm{b} D(l)=\left[(\pi a) /\left(2 b<S_{p}>\right)\right] l \int_{h_{N}}^{1}\left(1-V^{2} h^{2}\right)^{3 / 2} d h \quad$,

$<S_{p}>=(\pi / 2) a b\left(b / a+V^{-1} \arcsin (V)\right)$ then :

-if $l>2 b$

$D(l)=\left[(\pi a) /\left(16 b<S_{p}>V\right)\right] l\left[\begin{array}{c}\left(1-(2 b / l)^{2}\right)^{1 / 2} 2 b / l\left(3+8 b^{2} / l^{2}\right)+3 \arcsin \left(1-(2 b / l)^{2}\right)^{1 / 2} \\ -\left(3+2 b^{2} / a^{2}\right)\left(1-b^{2} / a^{2}\right)^{1 / 2} b / a-3 \arcsin \left(1-b^{2} / a^{2}\right)^{1 / 2}\end{array}\right]$

- if $l<2 b$

$D(l)=\left[(\pi a) /\left(16 b<S_{p}>V\right)\right] l\left[\left(3+2 b^{2} / a^{2}\right)\left(1-b^{2} / a^{2}\right)^{1 / 2} b / a+3 \arcsin \left(1-b^{2} / a^{2}\right)^{1 / 2}\right]$ 
B. Algorithm for chord length distribution:

Enter the number of spheres, their coordinates and radius, the number of projection events:

$\mathrm{N}, \mathrm{x}_{\mathrm{p} 1}, \mathrm{R}, \mathrm{Pl}$

$\operatorname{step}=\min (\mathrm{R}) / 100$

For $\mathrm{N}_{\mathrm{p}}=1,2, \ldots, \mathrm{Pl}$

Calculate the coordinates of each sphere in $N^{\text {th }}$ projected plan: $x_{p 2}$

Determine the coordinates of the 2 apexes belonging to the $2^{\text {nd }}$ diagonal of a rectangle containing the aggregate projection: $x_{\max }, x_{\min }$

For $1=1,2 \mathrm{n}(1)=$ integer $\left(\left(\mathrm{x}_{\max }(1)-\mathrm{x}_{\min }(1)\right) / \mathrm{step}\right)$;

For $\mathrm{g}_{1}=1, \ldots, \mathrm{n}(1)$

For $\mathrm{g}_{2}=1, \ldots, \mathrm{n}(2)$

chord $=0$

For $\mathrm{k}=1, \ldots, \mathrm{N}$

dist $=R(k)^{2}-\left(g_{1} \text { step }-x_{p 2}(k, 1)\right)^{2}-\left(g_{2} \text { step }-x_{p 2}(k, 2)\right)^{2}$

If dist $>0$ chord $=$ chord $+2 \sqrt{\text { dist }}$

End

End

End

End 
C. Calculation of the average scattering cross section for a spheroid particle:

In this appendix, the different lengths are kept with their dimensions.

The equation was used $(5)<C>=2\left\langle\iint_{[S p]}(1-\cos k l(m-1)) d S_{p}\right\rangle_{\theta}$ and insert the chord length distribution $D(l, \theta)$ :

$$
<C>=2\left\langle\iint_{[S p]}(1-\cos k l(m-1)) S_{p}(\theta) D(l, \theta) d l\right\rangle_{\theta}
$$

However, the chord length density (25) can be used and integrated over a solid angle:

$$
<C>=\int_{0}^{\pi / 2} \int_{0}^{l_{\max }(\theta)}(1-\cos k l(m-1)) S_{p}(\theta) C(\theta) l d l \cos \theta d \theta
$$

Nevertheless, a chord length distribution was calculated averaged on all the orientations in the simulations as expressed by the equation (27) in Annex A, so one may write:

$$
<C^{r}>=2<S_{p}>\int_{0}^{l_{\max }}(1-\cos k l(m-1)) D(l) d l=\int_{0}^{l_{\max }} \int_{0}^{\theta_{N}(l)}(1-\cos k l(m-1)) S_{p}(\theta) C(\theta) l \cos \theta d \theta d l
$$

We conclude that $\langle C\rangle=\left\langle C^{r}>\right.$ and calculate that:

If $\mathrm{a}<\mathrm{b}$ :

$<C>=<C^{r}>$

$$
=4 \pi a\left(a^{-2}-b^{-2}\right)^{-1 / 2} \int_{a / b}^{1} y^{-5}\left(1-y^{2}\right)^{-1 / 2}\left[y^{2} / 2-(q y \sin q y+\cos q y-1) / q^{2}\right] d y
$$

with $q=2 \frac{2 \pi}{\lambda}\left(m_{r}-1\right) b$

If $\mathrm{a}>\mathrm{b}$ :

$<C>=<C^{r}>$

$$
=4 \pi a\left(-a^{-2}+b^{-2}\right)^{-1 / 2} \int_{1}^{a / b} y^{-5}\left(y^{2}-1\right)^{-1 / 2}\left[y^{2} / 2-(q y \sin q y+\cos q y-1) / q^{2}\right] d y
$$




\section{Comparison of $\mathrm{AD}$ and $\mathrm{ADr}$ for $\mathrm{Al}_{2} \mathrm{O}_{3}$}

AD

Linear configuration

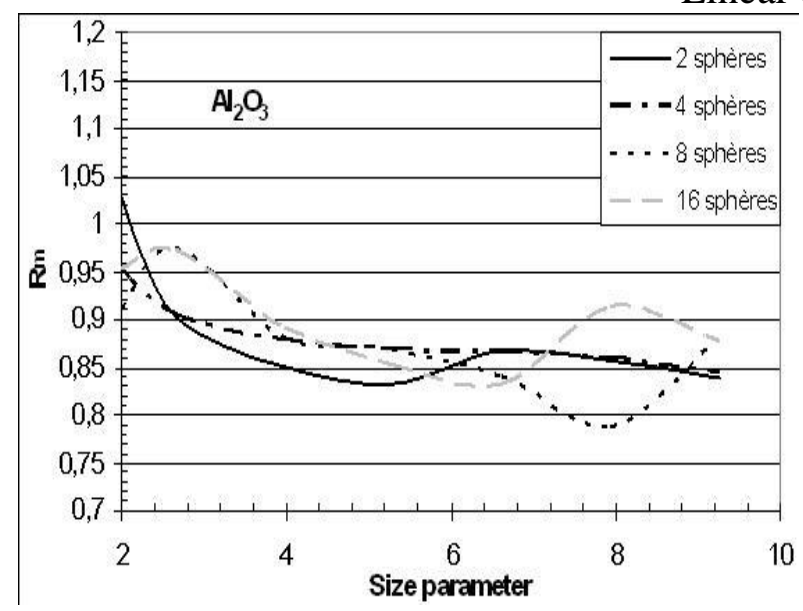

a)

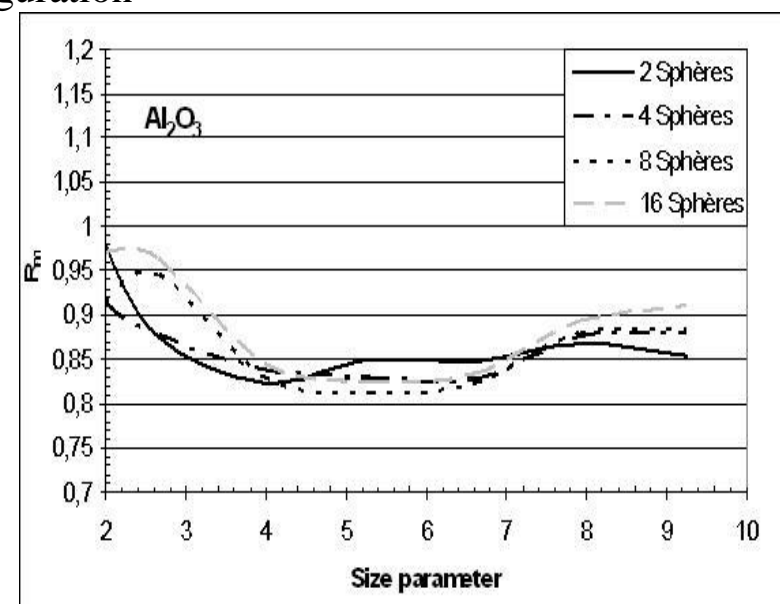

b)

Compact configuration

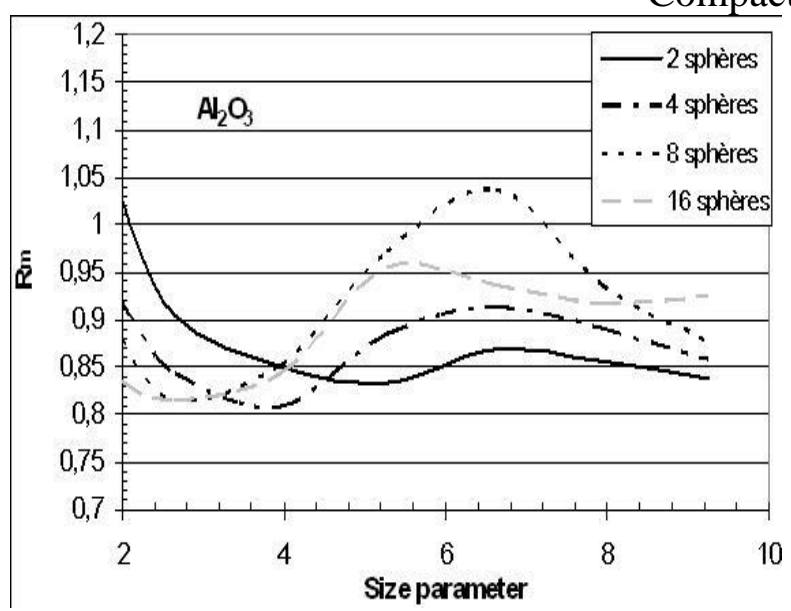

c)

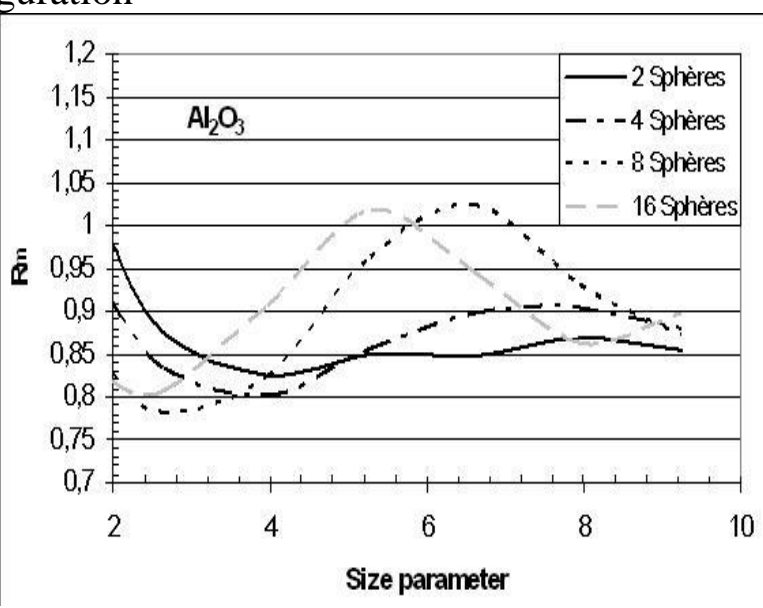

d)

Random configuration

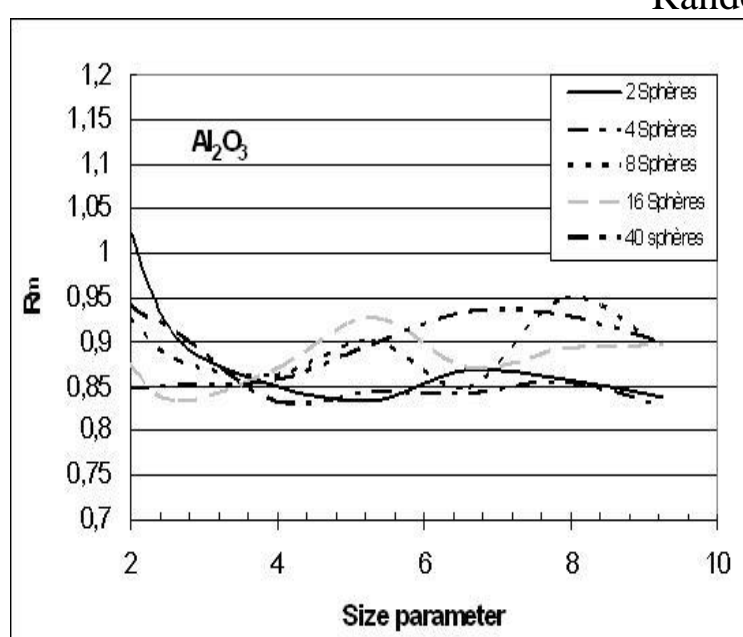

e)

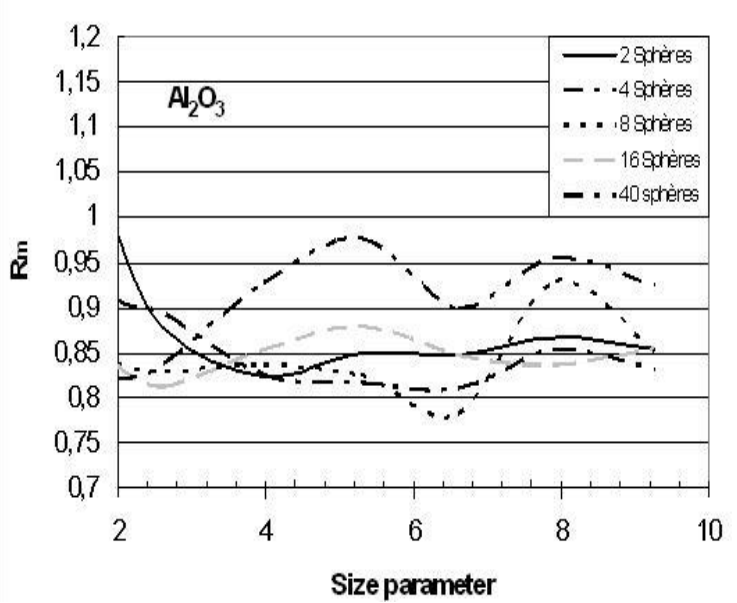

f)

Figure 14: $\mathrm{AD}\left(1^{\text {st }}\right.$ column $)$ and $\operatorname{ADr}\left(2^{\text {nd }}\right.$ column $)$ method as a function of the primary particle size parameter, for $\mathrm{Al}_{2} \mathrm{O}_{3}$ and 3 configurations: linear ( $1^{\text {st }}$ row), compact ( $2^{\text {nd }}$ row) and random ( $3^{\text {rd }}$ row $)$. 
Table 5: Comparison between $\mathrm{AD}$ and $\mathrm{ADr}$ for $\mathrm{Al}_{2} \mathrm{O}_{3}$, with the primary particle size range $x \in[2,10]$ and different cluster type.

\begin{tabular}{|c|l|c|c|c|}
\cline { 3 - 5 } \multicolumn{2}{c|}{} & linear configuration & compact configuration & random configuration \\
\hline \multirow{2}{*}{$\mathrm{R}$} & mean & 0,98 & 0,97 & 0,96 \\
\cline { 2 - 5 } & $\sigma$ & 0,04 & 0,04 & 0,07 \\
\hline
\end{tabular}




\section{Acknowledgments}

The authors would like to thank D. Y.-1. Xu for making his GMM code available.

\section{References}

\section{EN.REFLIST}

[1]Crawley GM, Cornil M, Di Benedetto D. Size analysis of fine particle suspensions by spectral turbidimetry: potential and limits. Powd Techn, 1997;91:197-208

[2] Kahnert FM. Numerical methods in electromagnetic scattering theory. JQSRT 2003;79$80: 775-824$

[3] Xu Y-1. Electromagnetic scattering by an aggregate of spheres. Appl Opt, 1995; 34:45734588 .

[4] Xu Y-l, Gustafson BAS. A generalized multiparticle Mie-solution: further experimental verification. JQSRT 2001;70:395-419.

[5] Xu Y-1, Khlebtsov NG. Orientation-averaging radiative properties of an arbitrary configuration of scatterers. JQSRT 2003;79-80:1121-1137.

[6] Jacquier S, Gruy F. Approximation of the light scattering cross-section for aggregated spherical non-absorbent particles. JQSRT 2007;106:133-144.

[7] Jacquier S. Approximated methods for the optical properties of spherical non-absorbent aggregated particles. PhD Thesis, 2006 ; Ecole Nationale Supérieure des Mines de Saint-Etienne.

[8] van der Hulst HC. Light scattering by small particles. New York: Wiley;1957

[9] Videen G, Chylek P. Anomalous diffraction approximation limits. Atmos Res 1998; 49:77-80.

[10] Liu C-L. Validity of anomalous diffraction approximation in $\mathrm{m}-\mathrm{X}$ domain. Atmos Res 1998;49:81-86.

[11] Chylek P, Klett JD. Absoption and scattering of electromagetic radiation by prismatic columns: anomalous diffraction approximation. J. Opt. Soc. Ameri. 1991;8:274-281.

[12] Sun W, Fu Q. Anomalous diffraction theory for arbitrarily oriented hexagonal crystals. JQSRT 1999; 63:727-737.

[13] Streekstra GJ, Hoekstra AG, Heethaar RM. Anomalous diffraction by arbitrarily oriented ellpsoids: applications in ektacytometry. Appl Opt 1994;33:7288-7296. 
[14] Liu Y, Arnott P, Hallett J. Anomalous diffraction theory for arbitrarily oriented finite circular cylinders and comparison with exact T-matrix results. Appl Opt 1998; 37(21):5019-5030.

[15] Sun W, Fu Q. Anomalous diffraction theory for randomly oriented nonspherical particles: a comparison between original and simplified solutions. JQSRT 2001;70: 737-747.

[16] Yang P, et al., A new look at anomalous diffraction theory (ADT): Algorithm in cumulative projected-area distribution domain and modified ADT. JQSRT 2004; 89: 421-442.

[17] Khlebtsov NG. Optics of fractal clusters in the anomalous diffraction approximation. J Mod Opt 1993;22:2221-2235. 